\title{
Ability of the PM3 Quantum-Mechanical Method to Model Intermolecular Hydrogen Bonding between Neutral Molecules
}

\author{
Marcus W. Jurema and George C. Shields* \\ Department of Chemistry, Lake Forest College, Lake Forest, Illinois 60045
}

Received 31 March 1992; accepted 23 July 1992

\begin{abstract}
The PM3 semiempirical quantum-mechanical method was found to systematically describe intermolecular hydrogen bonding in small polar molecules. PM3 shows charge transfer from the donor to acceptor molecules on the order of $0.02-0.06$ units of charge when strong hydrogen bonds are formed. The PM3 method is predictive; calculated hydrogen bond energies with an absolute magnitude greater than $2 \mathrm{kcal} \mathrm{mol}^{-1} \mathrm{suggest}^{-}$ that the global minimum is a hydrogen bonded complex; absolute energies less than $2 \mathrm{kcal} \mathrm{mol}^{-1} \mathrm{imply} \mathrm{that}^{-1}$ other van der Waals complexes are more stable. The geometries of the PM3 hydrogen bonded complexes agree with high-resolution spectroscopic observations, gas electron diffraction data, and high-level ab initio calculations. The main limitations in the PM3 method are the underestimation of hydrogen bond lengths by 0.1-0.2 $\AA$ for some systems and the underestimation of reliable experimental hydrogen bond energies by approximately $1-2 \mathrm{kcal} \mathrm{mol}^{-1}$. The PM3 method predicts that ammonia is a good hydrogen bond acceptor and a poor hydrogen donor when interacting with neutral molecules. Electronegativity differences between $\mathrm{F}, \mathrm{N}$, and $\mathrm{O}$ predict that donor strength follows the order $\mathrm{F}>\mathrm{O}>\mathrm{N}$ and acceptor strength follows the order $\mathrm{N}>\mathrm{O}>\mathrm{F}$. In the calculations presented in this article, the PM3 method mirrors these electronegativity differences, predicting the F-H- - $\mathrm{N}$ bond to be the strongest and the N-H- - F bond the weakest. It appears that the PM3 Hamiltonian is able to model hydrogen bonding because of the reduction of two-center repulsive forces brought about by the parameterization of the Gaussian core-core interactions. The ability of the PM3 method to model intermolecular hydrogen bonding means reasonably accurate quantum-mechanical calculations can be applied to small biologic systems. (c) 1993 by John Wiley \& Sons, Inc.
\end{abstract}

\section{INTRODUCTION}

The semiempirical quantum-mechanical methods developed by Dewar and coworkers ${ }^{1-4}$ have been successful at reproducing molecular energies, replicating molecular structures, and interpreting chemical reactions. ${ }^{5,6}$ These methods have been combined into one molecular orbital package, MOPAC. ${ }^{7}$ MOPAC allows for the calculation of wave functions by a selfconsistent field method using the Hartree-Fock formalism. MOPAC contains one Hamiltonian based upon the modified method of intermediate neglect of differential overlap approximation (MINDO/3) and three Hamiltonians based upon the modified neglect of diatomic differential overlap approximation (MNDO, AM1, and PM3). The PM3 model was developed using a new optimization procedure for quickly determining atomic parameters from experimental reference data. ${ }^{4}$ With this method, the average difference between calculated heats of formation and experimental values for 713 compounds is $8.2 \mathrm{kcal} \mathrm{mol}^{-1}$, as compared with 13.8 and 22.5 for

\footnotetext{
*Author to whom all correspondence should be addressed.
}

AM1 and MNDO, respectively. ${ }^{8}$ A thorough discussion of the modified INDO and NDDO methods can be found in ref. 6 .

Because $a b$ initio methods give quantitative results only for relatively small molecules, semiempirical procedures ${ }^{1-4}$ are used to study larger organic systems. ${ }^{6}$ MINDO/3, MNDO, and AM1 have limited application to biologic systems because the MINDO/ 3 and MNDO methods can not model hydrogen bonds and AM1 does not always reproduce intermolecular hydrogen bonds. AM1 calculations in general predict bifurcated intermolecular hydrogen bonds. ${ }^{9-23}$ Buemi et al. ${ }^{24}$ reported AM1 intermolecular hydrogen bonding energies for small molecule dimers but did not report the geometric results. Many authors have cautioned against the uncritical use of AM1 for calculations of intermolecular hydrogen bonded species. ${ }^{9,11,12,14,19,21,23,25}$ The AM1 method is useful for calculating intermolecular hydrogen bonds of many charged species. ${ }^{26,27}$

One of the best understood hydrogen bonded species is the water dimer. The structure of the water dimer has been established as a trans-linear $C_{s}$ equilibrium geometry by microwave spectroscopy experiments. ${ }^{28-32}$ The experimental structure is repli- 
cated by high-level $a b$ initio results. ${ }^{33-36}$ Yet, AM1 calculations fail to match experimental and $a b$ initio results, predicting the bifurcated structure. This failure of AM1 theory to describe this fundamental system has been discussed by Smith et al..$^{35}$ Rzepa and Yi have concluded that the tendency of AM1 to incorrectly favor bifurcated arrangements of water molecules arises when two or more hydrogen bonding sites are available. ${ }^{25}$

AM1 calculations have been useful in describing intramolecular hydrogen bonding, ${ }^{37-47}$ as well as proton affinities for a large series of aromatic compounds. ${ }^{48-50}$ The AM1 method reproduces experimental values for proton affinities of substituted pyridines better than the PM3 method.$^{50}$ Both the AM1 and PM3 methods have been shown to accurately predict gas-phase acidities and singlet-triplet gaps for a large number of molecules. ${ }^{51,52}$ In an AM1 study of the hydration of small anions, heats of hydration agreed with available experimental data but the AMI structures did not always agree well with available $a b$ initio calculations of these clusters. ${ }^{23}$

Stewart's PM3 method describes the intermolecular hydrogen bonding geometry of water dimers and intramolecular hydrogen bonding distances in salicylaldoximes. ${ }^{4}$ Juranic et al. ${ }^{19}$ demonstrated that the PM3 method realistically describes the geometries of ammonia-oxygen complexes solvated with water. In addition, Rzepa and $\mathrm{Yi}^{9}$ calculated hydrogen bonded structures of ammonia and water, a water trimer, and a water tetramer; their results are superior to those from AM1 calculations. The PM3 method has also been used to help investigate a uniquely strong $\mathrm{OH}--\mathrm{N}$ intramolecular hydrogen bond. ${ }^{53}$ Ventura et al ${ }^{54}$ performed a comparison of AM1, PM3, and Møller-Plesset ab initio calculations corrected for the basis set superposition error (BSSE) for the direct addition of water to formaldehyde. The authors conclude that the PM3 method is preferable to $a b$ initio calculations with a $4-31 \mathrm{G}$ basis set corrected for BSSE and to AM1 calculations for this reaction. ${ }^{54}$ Both PM3 and AM1 calculations predict vibrational frequencies with greater accuracy than MNDO or MINDO/3, and the best method to use depends upon the type of vibrational mode being investigated..$^{55,56}$

Accurate $a b$ initio calculations replicating hydrogen bonding systems are expensive, and the correct kind of $a b$ initio calculation is not obvious. ${ }^{9,35,57-62}$ The difficulty of calculating the interaction energy of two weakly bound molecules originates from the small magnitude of the quantity sought relative to the BSSE. ${ }^{63}$ Applications of quantum-mechanical methods to biologic systems will be largely confined to the faster semiempirical methods in the near future provided that these methods adequately describe hydrogen bonding. While high-level $a b$ initio calculations will remain the method of choice to study hydrogen bonding of small molecules, for biologic molecules a successful description of inter- molecular hydrogen bonding by a semiempirical method should be useful. In this article, results of calculations with the PM3 semiempirical method are presented for 32 intermolecular hydrogen bonding systems composed of neutral molecules.

\section{METHOD}

Fourteen polar molecules and 32 neutral intermolecular hydrogen bonded systems were built with Alchemy II (Tripos Associates, St. Louis, MO) or Chem 3D Plus software (Cambridge Scientific Computing, Inc., Cambridge, MA) on a Macintosh II computer (Apple Computer, Inc., Cupertino, CA). The 14 monomers were fully geometry optimized with the AM1 and PM3 methods. Complexes were created from the monomers with initial hydrogen bond angles of $180^{\circ}$ and hydrogen bond distances of $1.7 \AA$. These structures were input coordinates for AM1 and PM3 calculations of geometries, heats of formation $\left(\Delta H_{f 298 \mathrm{~K}}^{\circ}\right)$, and atomic charges using MOPAC 5.0 software. $^{7}$ Additional configurations were used to explore the potential energy surfaces of selected complexes.

The criterion for terminating all optimizations was increased 100-fold over normal MOPAC limits using the PRECISE option. Unrestricted Hartree-Fock calculations were performed for exploration of the hydrogen bonded potential energy surfaces. All structures were characterized as stationary points and true minima on the potential energy surfaces using the keyword FORCE. A stationary point is described if the first derivatives of the energy with respect to changes in the geometry are zero. The criterion for a minimum is that all eigenvalues of the Hessian matrix are positive. ${ }^{6}$ The FORCE calculation is essential for characterization of these weak intermolecular interactions, as the potential energy surface for a hydrogen bonded complex is fairly flat, with minima separated by a few kilocalories per mole from each other and the separated monomers.

Energy partitioning of the one- and two-center terms was performed for six different geometries of water dimers using the keywords ENPART and 1SCF. For each geometry, the calculation was repeated using the PM3, AM1, and MNDO Hamiltonians.

The enthalpies of association (heat liberated) for the hydrogen bonded complexes were determined at $298 \mathrm{~K}$ by determining the difference between the heats of formation for the unassociated monomers and those for the complexes. The hydrogen bond geometries were checked by inspection and calculated PM3 hydrogen bond energies determined by dividing the enthalpy of association by the number of hydrogen bonds present in the system. All calculations were performed on a microVAX 3400 .

\section{RESULTS}

The AM1 and PM3 calculated heats of formation for 14 polar molecules, and available experimental val- 
Table I. Calculated and experimental heats of formation for 14 molecules that participate in hydrogen bonding.

\begin{tabular}{lccc}
\hline & $\Delta H_{f 298 \mathrm{~K}}^{\text {o }}\left(\mathrm{kcal} \mathrm{mol}^{-1}\right)$ & \\
\cline { 2 - 4 } Molecule & $\mathrm{PM} 3$ & $\mathrm{AM} 1$ & Experiment \\
\hline $\mathrm{H}_{2} \mathrm{O}$ & -53.4 & -59.2 & -57.8 \\
$\mathrm{CH}_{3} \mathrm{OH}$ & -51.9 & -57.0 & -48.2 \\
$\mathrm{HCOOH}$ & -94.4 & -97.4 & -90.5 \\
$\mathrm{CH}_{3} \mathrm{COOH}$ & -101.9 & -103.0 & -103 \\
$\mathrm{C}_{6} \mathrm{H}_{6} \mathrm{COOH}$ & -66.2 & -68.0 & -66.2 \\
$\mathrm{CH}_{2} \mathrm{O}$ & -34.1 & -31.5 & -26 \\
$\mathrm{CO}_{2}$ & -85.0 & -79.8 & -94.0 \\
$\mathrm{NH}_{3}$ & -3.1 & -7.3 & -11 \\
$\mathrm{C}_{2} \mathrm{H}_{7} \mathrm{~N}$ & -7.9 & -5.6 & -4.4 \\
$\mathrm{C}_{3} \mathrm{H}_{4} \mathrm{~N}_{2}$ & 48.8 & 65.6 & 44 \\
$\mathrm{C}_{5} \mathrm{H}_{5} \mathrm{~N}$ & 30.4 & 32.0 & 33 \\
$\mathrm{NH}_{2} \mathrm{CHO}$ & -41.8 & -44.8 & -44 \\
$\mathrm{C}_{5} \mathrm{H}_{5} \mathrm{NO}$ & -15.6 & -11.3 & -18 \\
$\mathrm{HF}$ & -62.7 & -74.3 & -65.1 \\
\hline
\end{tabular}

All experimental values are from ref. 64 except $\mathrm{CO}_{2}$, taken from ref. 65 .

ues, ${ }^{64,65}$ are presented in Table I. The average difference between AM1 enthalpies and experimental enthalpies is $4.5 \mathrm{kcal} \mathrm{mol}^{-1}$ with a standard deviation of $1.22 \mathrm{kcal} \mathrm{mol}^{-1}$. PM3 has an average error of 4 kcal mol ${ }^{-1}$ with a standard deviation of $0.74 \mathrm{kcal}$ $\mathrm{mol}^{-1}$. The methods of Dewar and coworkers ${ }^{1-4}$ have been successful because of their general applicability to a wide variety of molecular systems, with each new model improving the overall ability to replicate diverse systems. For the molecules listed in Table I, the PM3 calculations for $\mathrm{C}_{3} \mathrm{H}_{4} \mathrm{~N}_{2}$ and $\mathrm{CO}_{2}$ are notably more accurate than are the $\mathrm{AM} 1$ results.

Thirty-two neutral complexes built from the species in Table I were fully geometry optimized with the AM1 and PM3 methods; the results of the PM3 calculations are presented in Table II. Table II lists the heats of formation for these hydrogen bonded complexes and the calculated heats of association for these hydrogen bonded systems. A bold number is listed for each system to facilitate comparison of energies with complexes presented in the figures.

Table III organizes information into different categories, including types of hydrogen bonds, the identity of the donor/acceptor pair, the distance between donor and acceptor atoms, the charge transfer between the donor and acceptor molecules in the complex, and the calculated PM3 hydrogen bond energy. Also included in Table III are available experimental

Table II. Calculated PM3 heats of formation and enthalpies of association for hydrogen bonded complexes.

\begin{tabular}{|c|c|c|c|}
\hline System (donor/acceptor) & Complex & $\begin{array}{c}\text { PM3 } \Delta H_{f}^{\circ} 298 \mathrm{~K} \\
\left(\mathrm{kcal} \mathrm{mol}^{-1}\right)\end{array}$ & $\begin{array}{l}\text { Enthalpy of association } \\
\text { for complex relative to the } \\
\text { separated monomers (kcal } \\
\mathrm{mol}^{-1} \text { ) }\end{array}$ \\
\hline $\mathrm{H}_{2} \mathrm{O} / \mathrm{CH}_{2} \mathrm{O}$ & $1 \mathbf{b}$ & -90.25 & -2.75 \\
\hline $\mathrm{H}_{2} \mathrm{O} / \mathrm{H}_{2} \mathrm{O}$ & 2 & -110.35 & -3.55 \\
\hline$\left(\mathrm{H}_{2} \mathrm{O}\right)_{3}$ & $\overline{3}$ & -169.24 & -9.04 \\
\hline$\left(\mathrm{H}_{2} \mathrm{O}\right)_{3}$ cyclic & 4 & -170.35 & -10.14 \\
\hline$\left(\mathrm{H}_{2} \mathrm{O}\right)_{3} 1$ donor & $\mathbf{5}$ & -166.26 & -6.06 \\
\hline$\left(\mathrm{H}_{2} \mathrm{O}\right)_{3} 1$ acceptor & 6 & -166.96 & -6.76 \\
\hline$\left(\mathrm{H}_{2} \mathrm{O}\right)_{5}$ & 7 & -284.93 & -17.93 \\
\hline $\mathrm{H}_{2} \mathrm{O} / \mathrm{CH}_{3} \mathrm{OH}$ & $\mathbf{8}$ & -108.23 & -2.93 \\
\hline $\mathrm{H}_{2} \mathrm{O} / \mathrm{CO}_{2}$ & $\mathbf{9}$ & -139.37 & -0.97 \\
\hline $\mathrm{CH}_{3} \mathrm{OH} / \mathrm{CH}_{3} \mathrm{OH}$ & 10 & -106.35 & -2.55 \\
\hline $\mathrm{CH}_{3} \mathrm{OH} / \mathrm{H}_{2} \mathrm{O}$ & 11 & -108.51 & -3.21 \\
\hline $\mathrm{HCOOH} / \mathrm{HCOOH}$ & 12 & -197.47 & -8.68 \\
\hline $\mathrm{CH}_{3} \mathrm{COOH} / \mathrm{CH}_{3} \mathrm{COOH}$ & 13 & -212.84 & -9.05 \\
\hline $\mathrm{C}_{6} \mathrm{H}_{6} \mathrm{COOH} / \mathrm{C}_{6} \mathrm{H}_{6} \mathrm{COOH}$ & 14 & -141.16 & -8.76 \\
\hline $\mathrm{NH}_{3} / \mathrm{NH}_{3}$ & 15 & -6.01 & 0.19 \\
\hline $\mathrm{C}_{2} \mathrm{H}_{7} \mathrm{~N} / \mathrm{NH}_{3}$ & 16 & -11.07 & -0.07 \\
\hline$\left(\mathrm{C}_{3} \mathrm{H}_{4} \mathrm{~N}_{2}\right)_{3}$ cyclic & 17 & 131.65 & -14.76 \\
\hline $\mathrm{H}_{2} \mathrm{O} / \mathrm{C}_{5} \mathrm{H}_{5} \mathrm{~N}$ & 18 & -25.15 & -2.50 \\
\hline $\mathrm{CH}_{3} \mathrm{OH} / \mathrm{C}_{5} \mathrm{H}_{5} \mathrm{~N}$ & 19 & -23.55 & -2.05 \\
\hline $\mathrm{H}_{2} \mathrm{O} / \mathrm{NH}_{3}$ & 20 & -59.53 & -3.03 \\
\hline $\mathrm{CH}_{3} \mathrm{OH} / \mathrm{NH}_{3}$ & 21 & -57.83 & -2.83 \\
\hline $\mathrm{HCOOH} / \mathrm{NH}_{3}$ & 22 & -98.29 & -0.79 \\
\hline $\mathrm{CH}_{3} \mathrm{COOH} / \mathrm{NH}_{3}$ & 23 & -107.50 & -2.50 \\
\hline $\mathrm{NH}_{2} \mathrm{CHO} / \mathrm{NH}_{2} \mathrm{CHO}$ & 24 & -88.29 & -4.69 \\
\hline $\mathrm{C}_{5} \mathrm{H}_{5} \mathrm{NO} / \mathrm{C}_{5} \mathrm{H}_{5} \mathrm{NO}$ & 25 & -41.03 & -9.83 \\
\hline $\mathrm{NH}_{3} / \mathrm{H}_{2} \mathrm{O}$ & 26 & -57.37 & -0.87 \\
\hline $\mathrm{NH}_{3} / \mathrm{CH}_{3} \mathrm{OH}$ & 27 & -55.21 & -0.21 \\
\hline $\mathrm{NH}_{3} / \mathrm{HCOOH}$ & 28 & -97.93 & -0.43 \\
\hline $\mathrm{H}_{2} \mathrm{O} / \mathrm{HF}$ & 29 & -120.12 & -4.02 \\
\hline $\mathrm{HF} / \mathrm{H}_{2} \mathrm{O}$ & $\mathbf{3 0}$ & -121.61 & -5.51 \\
\hline $\mathrm{HF} / \mathrm{NH}_{3}$ & 31 & -71.72 & -5.92 \\
\hline $\mathrm{NH}_{3} / \mathrm{HF}$ & 32 & -67.30 & -1.50 \\
\hline
\end{tabular}

Enthalpies of association were obtained by difference from the $\Delta H_{f 298 \mathrm{~K}}^{\circ}$ of the hydrogen bonded complexes and the sums of $\Delta H_{f 298 \mathrm{~K}}^{\circ}$ for the monomers (given in Table 1). 
Table III. Types of hydrogen bonds, distance between donor and acceptor atoms, charge transferred from donor molecule to acceptor molecule upon complex formation, and calculated and experimental hydrogen bond energies for the 32 hydrogen bonded complexes investigated with the PM3 quantum mechanical method.

\begin{tabular}{|c|c|c|c|c|c|c|c|c|}
\hline \multirow[b]{2}{*}{ Type } & \multirow[b]{2}{*}{ Donor (D) } & \multirow[b]{2}{*}{ Acceptor (A) } & \multirow[b]{2}{*}{ Complex } & \multirow[b]{2}{*}{$\mathrm{R}(\mathrm{D}-\mathrm{A})(\AA)$} & \multirow[b]{2}{*}{ Charge transfer } & \multicolumn{2}{|c|}{$\begin{array}{l}\text { H bond energy } \\
\left(\mathrm{kcal} \mathrm{mol}^{-1}\right)\end{array}$} & \multirow[b]{2}{*}{ Ref. } \\
\hline & & & & & & PM3 & Exp. & \\
\hline \multirow[t]{23}{*}{$\mathrm{O}-\mathrm{H}-\mathrm{O}$} & $\mathrm{H}_{2} \mathrm{O}$ & $\mathrm{H}_{2} \mathrm{O}$ & 2 & 2.77 & 0.0221 & -3.55 & -4.4 to -5.4 & $66-69$ \\
\hline & $\begin{array}{l}\mathrm{H}_{2} \mathrm{O}(2 \mathrm{D}) \\
\text { (open trimer) }\end{array}$ & $\mathrm{H}_{2} \mathrm{O}(2 \mathrm{~A})$ & $\mathbf{3}$ & 2.74 & $\begin{array}{c}-0.0292(\mathrm{D}) \\
0.0014(\mathrm{D}, \mathrm{A})\end{array}$ & -4.52 & & \\
\hline & & & & 2.71 & 0.0278 & & & \\
\hline & $\mathrm{H}_{2} \mathrm{O}(3 \mathrm{D})$ & $\mathrm{H}_{2} \mathrm{O}(3 \mathrm{~A})$ & 4 & 2.67 & $0.0009(\mathrm{D}, \mathrm{A})$ & -3.38 & & \\
\hline & (cyclic trimer) & & & 2.67 & $0.0006(\mathrm{D}, \mathrm{A})$ & & & \\
\hline & & & & 2.67 & $-0.0015(\mathrm{D}, \mathrm{A})$ & & & \\
\hline & $\mathrm{H}_{2} \mathrm{O}(1 \mathrm{D})$ & $\mathrm{H}_{2} \mathrm{O}(2 \mathrm{~A})$ & 5 & 2.77 & $\begin{array}{l}0.0214 \\
-0.0430(\mathrm{D})\end{array}$ & -3.03 & & \\
\hline & & & & 2.77 & 0.0214 & & & \\
\hline & $\mathrm{H}_{2} \mathrm{O}(2 \mathrm{D})$ & $\mathrm{H}_{2} \mathrm{O}(1 \mathrm{~A})$ & 6 & 2.76 & $\begin{array}{c}-0.0171(\mathrm{D}) \\
0.0344\end{array}$ & -3.38 & & \\
\hline & & & & 2.76 & -0.0171 (D) & & & \\
\hline & $\mathrm{H}_{2} \mathrm{O}(3 \mathrm{D})$ & $\mathrm{H}_{2} \mathrm{O}(3 \mathrm{~A})$ & 7 & 2.71 & 0.0301 & -4.48 & & \\
\hline & (open pentamer) & & & 2.71 & 0.0301 & & & \\
\hline & & & & & $-0.0007(\mathrm{D}, \mathrm{A})$ & & & \\
\hline & & & & 2.74 & $-0.0298(\mathrm{D})$ & & & \\
\hline & & & & 2.74 & -0.0298 (D) & & & \\
\hline & $\mathrm{H}_{2} \mathrm{O}$ & $\mathrm{CH}_{3} \mathrm{OH}$ & 8 & 2.78 & 0.0224 & -2.93 & & \\
\hline & $\mathrm{H}_{2} \mathrm{O}$ & $\mathrm{CH}_{2} \mathrm{O}$ & $1 b$ & 2.78 & 0.0246 & -2.75 & & \\
\hline & $\mathrm{H}_{2} \mathrm{O}$ & $\mathrm{CO}_{2}$ & 9 & 2.79 & 0.0151 & -0.97 & & \\
\hline & $\mathrm{CH}_{3} \mathrm{OH}$ & $\mathrm{CH}_{3} \mathrm{OH}$ & 10 & 2.78 & 0.0219 & $-2,55$ & -3.2 to -7.3 & 66,70 \\
\hline & $\mathrm{CH}_{3} \mathrm{OH}$ & $\mathrm{H}_{2} \mathrm{O}$ & 11 & 2.76 & 0.0219 & -3.21 & & \\
\hline & $\mathrm{HCOOH}$ & $\mathrm{HCOOH}$ & 12 & 2.74 & $0.0001(\mathrm{D}, \mathrm{A})$ & -4.34 & -5.85 & 71 \\
\hline & $\mathrm{CH}_{3} \mathrm{COOH}$ & $\mathrm{CH}_{3} \mathrm{COOH}$ & 13 & 2.74 & $0.0000(\mathrm{D}, \mathrm{A})$ & -4.52 & -6.4 to -8.4 & $66,67,72$ \\
\hline & $\mathrm{C}_{6} \mathrm{H}_{5} \mathrm{COOH}$ & $\mathrm{C}_{6} \mathrm{H}_{5} \mathrm{COOH}$ & 14 & 2.74 & $0.0001(\mathrm{D}, \mathrm{A})$ & -4.38 & -7.3 & 73 \\
\hline \multirow[t]{5}{*}{$\mathrm{N}-\mathrm{H}-\mathrm{N}$} & $\mathrm{NH}_{3}$ & $\mathrm{NH}_{3}$ & 15 & 2.92 & 0.0295 & 0.19 & & \\
\hline & $\mathrm{C}_{2} \mathrm{H}_{7} \mathrm{~N}$ & $\mathrm{NH}_{3}$ & 16 & 2.91 & 0.0345 & -0.07 & & \\
\hline & $\mathrm{C}_{3} \mathrm{H}_{4} \mathrm{~N}_{2}$ & $\mathrm{C}_{3} \mathrm{H}_{4} \mathrm{~N}_{2}$ & 17 & 2.81 & $0.0015(\mathrm{D}, \mathrm{A})$ & -4.92 & & \\
\hline & (trimer) & & & 2.80 & $-0.0002(\mathrm{D}, \mathrm{A})$ & & & \\
\hline & & & & 2.80 & $-0.0015(\mathrm{D}, \mathrm{A})$ & & & \\
\hline \multirow[t]{6}{*}{$\mathrm{O}-\mathrm{H}-\mathrm{N}$} & $\mathrm{H}_{2} \mathrm{O}$ & $\mathrm{C}_{5} \mathrm{H}_{5} \mathrm{~N}$ & 18 & 2.80 & 0.0381 & -2.15 & & \\
\hline & $\mathrm{CH}_{3} \mathrm{OH}$ & $\mathrm{C}_{5} \mathrm{H}_{5} \mathrm{~N}$ & 19 & 2.80 & 0.0379 & -2.05 & -4.4 & 74 \\
\hline & $\mathrm{H}_{2} \mathrm{O}$ & $\mathrm{NH}_{3}$ & 20 & 2.79 & 0.0446 & -3.03 & & \\
\hline & $\mathrm{CH}_{3} \mathrm{OH}$ & $\mathrm{NH}_{3}$ & 21 & 2.79 & 0.0455 & -2.83 & & \\
\hline & $\mathrm{HCOOH}$ & $\mathrm{NH}_{3}$ & 22 & 2.77 & 0.0559 & -0.79 & & \\
\hline & $\mathrm{CH}_{3} \mathrm{COOH}$ & $\mathrm{NH}_{3}$ & 23 & 2.77 & 0.0544 & -2.50 & & \\
\hline \multirow[t]{5}{*}{$\mathrm{N}-\mathrm{H}-\mathrm{O}$} & $\mathrm{NH}_{2} \mathrm{CHO}$ & $\mathrm{NH}_{2} \mathrm{CHO}$ & 24 & 2.83 & 0.0004 & -2.34 & $-7($ solid $)$ & 67 \\
\hline & $\mathrm{C}_{5} \mathrm{H}_{5} \mathrm{NO}$ & $\mathrm{C}_{5} \mathrm{H}_{5} \mathrm{NO}$ & 25 & 2.80 & 0.0001 & -4.92 & & \\
\hline & $\mathrm{NH}_{3}$ & $\mathrm{H}_{2} \mathrm{O}$ & 26 & 2.87 & 0.0130 & -0.87 & & \\
\hline & $\mathrm{NH}_{3}$ & $\mathrm{CH}_{3} \mathrm{OH}$ & 27 & 2.88 & 0.0137 & -0.21 & & \\
\hline & $\mathrm{NH}_{3}$ & $\mathrm{HCOOH}$ & 28 & 2.88 & 0.0178 & -0.43 & & \\
\hline $\mathrm{O}-\mathrm{H}-\mathrm{F}$ & $\mathrm{H}_{2} \mathrm{O}$ & $\mathrm{HF}$ & 29 & 2.72 & 0.0230 & -4.02 & & \\
\hline $\mathrm{F}-\mathrm{H}-\mathrm{O}$ & $\mathrm{HF}$ & $\mathrm{H}_{2} \mathrm{O}$ & 30 & 2.68 & 0.0272 & -5.51 & -7.2 & 69 \\
\hline F-H-N & $\mathrm{HF}$ & $\mathrm{NH}_{3}$ & 31 & 2.74 & 0.0588 & -5.92 & & \\
\hline $\mathrm{N}-\mathrm{H}-\mathrm{F}$ & $\mathrm{NH}_{3}$ & $\mathrm{HF}$ & 32 & 2.81 & 0.0166 & -1.50 & & \\
\hline
\end{tabular}

hydrogen bond energies and appropriate references. ${ }^{66-74}$ Table IV contains a detailed comparison of experimental, ${ }^{75} a b$ initio, ${ }^{76}$ and PM3 results for the formic acid dimer.

Fully optimized hydrogen bonded structures of the water-formaldehyde complexes, where the water molecule donates a hydrogen to the oxygen in formaldehyde, are shown in Figure 1. Figure 2 displays the results of a reaction path calculation for the water dimer. These two figures illustrate the general differences between the AM1 and PM3 models. Rel- evant bond distances, bond angles, and atomic charges are included in these diagrams. To understand the parameters associated with the success of the PM3 method in reproducing hydrogen bonds, six complexes of water molecules were calculated and results are presented in Figure 3. Figure 4 displays the PM3 results for other complexes with $\mathrm{O}-\mathrm{H}-\mathrm{-}_{-} \mathrm{O}$, $\mathrm{N}-\mathrm{H}-\mathrm{-} \mathrm{-N}^{\mathrm{N}} \mathrm{O}-\mathrm{H}-\mathrm{-}-\mathrm{N}$, and $\mathrm{N}-\mathrm{H}-\mathrm{-}^{-\mathrm{O}}$ hydrogen bonds. Figure 4 also contains the results for systems involving a fluorine atom and the global minimum for the ammonia dimer system. 
Table IV. Comparison of PM3, experimental (ref. 75), and $D Z+P a b$ initio (ref. 76) bond distances and bond angles for the formic acid dimer.

\begin{tabular}{lccr}
\hline $\begin{array}{c}\text { Geometrical } \\
\text { parameter }\end{array}$ & PM3 & Exp. & $D Z+P$ \\
\hline$r(\mathrm{C}=\mathrm{O})$ & 1.221 & $1.220 \pm .003$ & 1.199 \\
$r(\mathrm{C}-\mathrm{O})$ & 1.328 & $1.323 \pm .003$ & 1.300 \\
$r(\mathrm{C}-\mathrm{H})$ & 1.095 & $1.082 \pm .021$ & 1.087 \\
$r(\mathrm{O}-\mathrm{H})$ & 0.969 & $1.036 \pm .017$ & 0.966 \\
$r(\mathrm{O}-\mathrm{H}--\mathrm{O})$ & 2.74 & $2.703 \pm .007$ & 2.779 \\
$r(\mathrm{O}-\mathrm{O})$ & 2.193 & $2.268 \pm .004$ & 2.227 \\
$<(\mathrm{C}-\mathrm{O}-\mathrm{H})-$ & 113.4 & $108.5 \pm .4$ & 111.0 \\
$<(\mathrm{O}=\mathrm{C}-\mathrm{O})$ & 118.6 & $126.2 \pm .48$ & 125.9 \\
$<(\mathrm{H}-\mathrm{C}=\mathrm{O})$ & 127.9 & $115.4 \pm 3.1$ & 122.2 \\
$<(\mathrm{O}-\mathrm{H}--\mathrm{O})$ & 177.4 & $180^{\mathrm{a}}$ & 172.7 \\
\hline
\end{tabular}

Bond lengths in $\AA$, bond angles in degrees.

a Geometric parameter assumed in the refinement of the electron diffraction data.

A label is used for each complex in the figures for ease in correlating the energies in Tables II and III with the appropriate hydrogen bonded complexes. The Chem 3D Plus and Chemdraw software packages (Cambridge Scientific Computing) were used in conjunction with an Apple LaserWriter to produce and print the final geometry-optimized structures.

\section{DISCUSSION}

Hydrogen bonding was recognized by Huggins ${ }^{77}$ in 1919 and Latimer and Rodebush in $1920 .^{78}$ The general features of hydrogen bonding interactions have

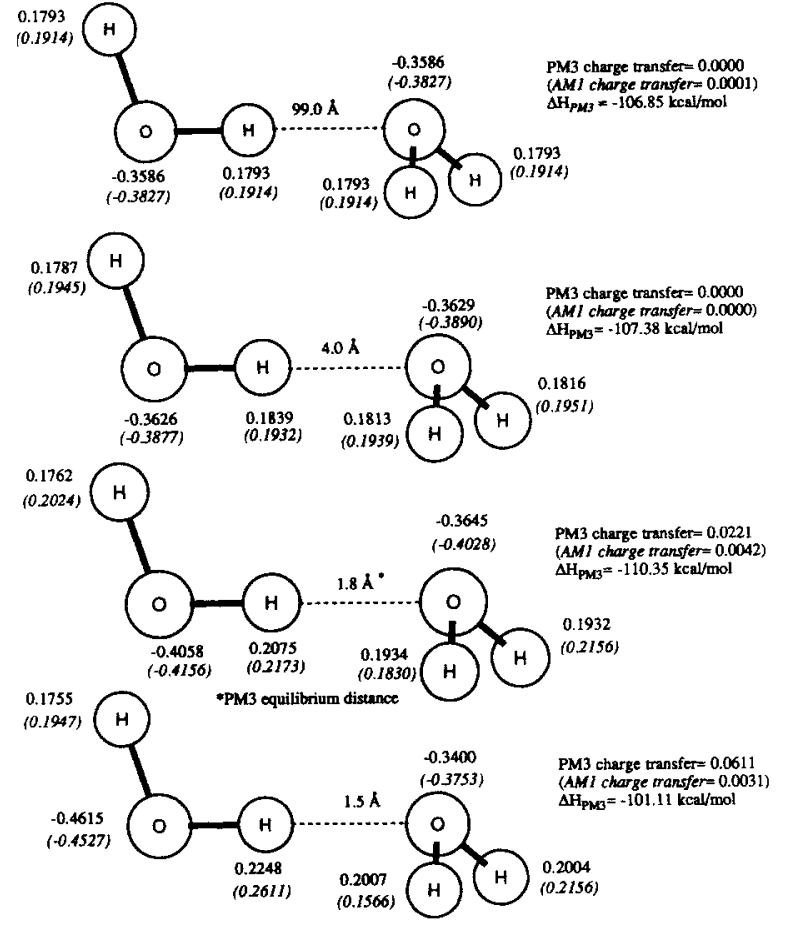

Figure 2. Selected geometries of the water dimer reaction coordinate as calculated by PM3. Atomic charges are given next to each atom; the overall charge transfer and heat of formation for each complex are listed to the right of each structure. The AMl values, in parentheses, result from an AM1 reaction coordinate calculation where the angle of approach is constrained to the PM3 minimum structure 2.

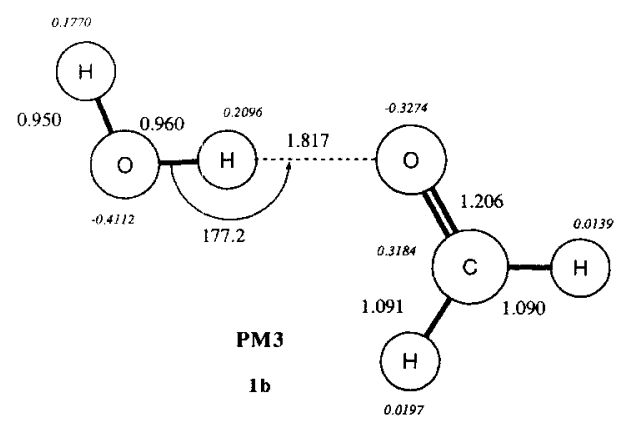

Figure 1. Geometries of the water/formaldehyde hydrogen bonded complex. Bond distances in $\AA$, bond angles in degrees, and atomic charges presented in italics.

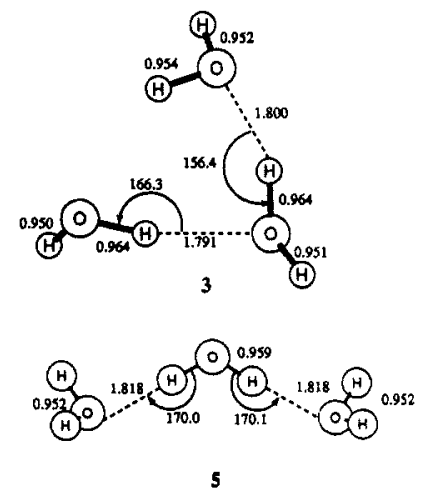

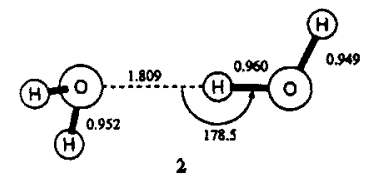

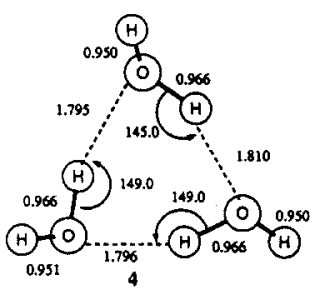<smiles>COCCOCCOC</smiles>

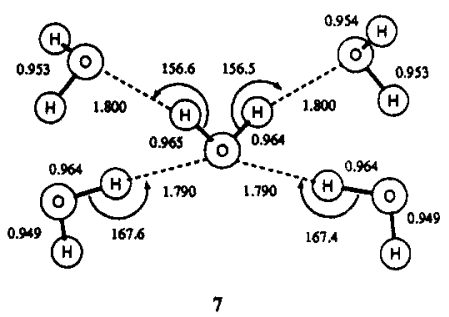

Figure 3. PM3 geometries for selected hydrogen bonded water complexes. Bond distances in $\AA$, bond angles in degrees. 

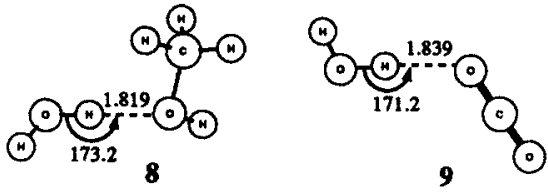

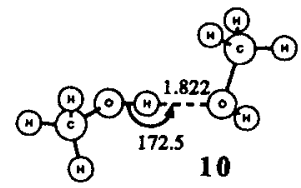<smiles>O=C(O)C(=O)Oc1cc2cc(c1)C(=O)C2=O</smiles>

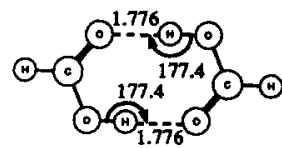

12

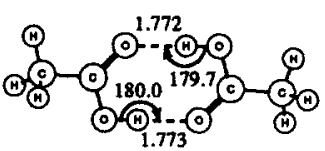

13

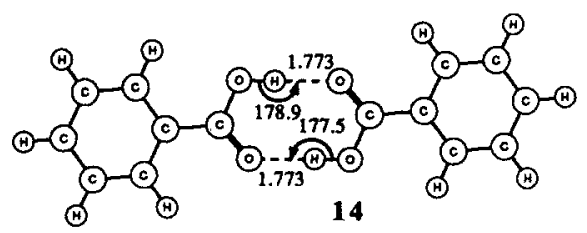

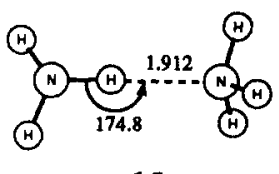

15

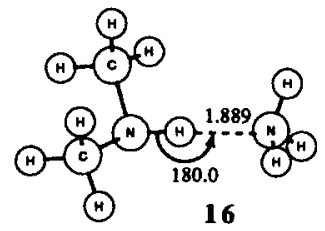

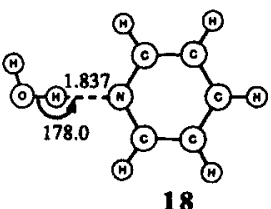

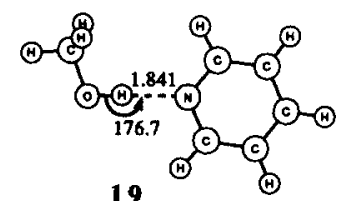

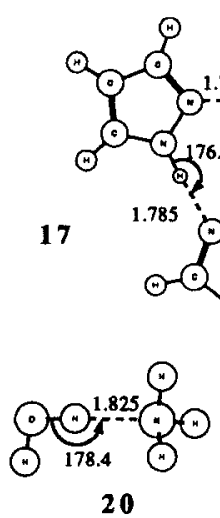

14<smiles>C1CCCC1</smiles><smiles>[O]</smiles>

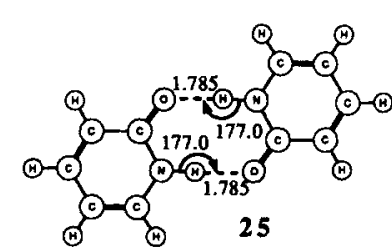

22

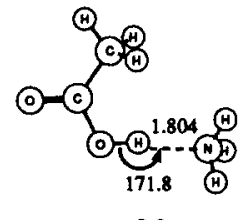

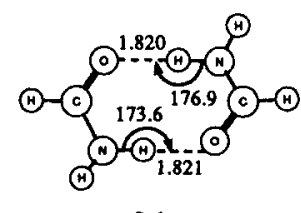

24

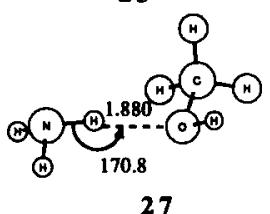

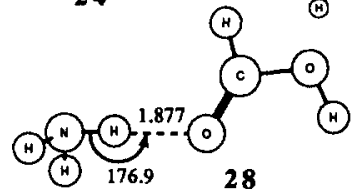<smiles>O=CC1CCCCC1</smiles>

29<smiles>O=CC(=O)C=Cc1ccccc1</smiles>

30

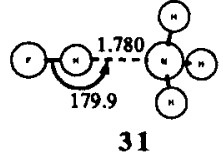

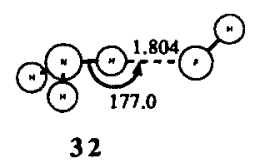

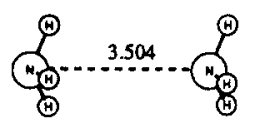

Figure 4. PM3 geometries for selected O-H- - -O, N-H- - -N, O-H- - -N, and N-H- - -O hydrogen bonded systems and for systems involving the fluorine atom. At the bottom right is the PM3 geometry for the global minimum of the ammonia dimer. Hydrogen bond distances in $\AA$, hydrogen bond angles in degrees.

been thoroughly studied and are well known, ${ }^{66,79}$ yet detailed knowledge of specific systematic differences is an area of active research. ${ }^{80}$ Precise values for the energetics of hydrogen bond formation are difficult to measure experimentally. Valuable insights into the detailed structure of hydrogen bonded systems have been obtained by high-resolution infrared and microwave spectroscopy experiments. In the following discussion, results of PM3 and AM1 calculations of hydrogen bonded structures and hydrogen bond energies are compared with experimental and theoretical values. Comparisons with recent experimental and high-level $a b$ initio investigations are emphasized.

\section{Comparison of the PM3 and AM1 Methods}

Figure 1 displays the hydrogen bonding geometries and atomic charges for the intermolecular system where water donates a hydrogen to formaldehyde. The AMl minimum energy structure 1a has two hydrogen bond angles of $108^{\circ}$ and two hydrogen to acceptor distances of approximately $2.24 \AA$. The oxygen-oxygen distance is $2.706 \AA$. The PM3 structure $1 \mathrm{~b}$ has a hydrogen bond distance of $1.817 \AA$, a bond angle of $177.2^{\circ}$, and an oxygen-oxygen separation distance of $2.78 \AA$. This structure has been previously reported ${ }^{54}$ The association energy of the AM1 complex is $-4.0 \mathrm{kcal} \mathrm{mol}^{-1}$; the PM3 energy of associ- 
ation is $-2.75 \mathrm{kcal} \mathrm{mol}^{-1}$ (Table II). Although the absolute value of the energy of interaction is greater for the AM1 complex 1a, Figure 1 illustrates that only the PM3 complex 1b assumes a classic hydrogen bond configuration, that is, with a hydrogen bond angle between 140 and $180^{\circ}$, and where the distance between the hydrogen and acceptor atoms is significantly less than the sum of their van der Waals radii. The distance between the hydrogen and donor atom is lengthened for the PM3 complex as expected upon hydrogen bond formation. The charges on the atoms, in italics in the figure, are more negative for the donor and acceptor oxygen, and the carbon atom is more positive, when calculated by the PM3 method. The nonsymmetrical PM3 charge distribution is critical for formation of hydrogen bonds.

In the AM1 calculation, a bifurcated conformation is favored with each hydrogen of the water approximately $2.24 \AA$ from the oxygen acceptor atom in formaldehyde. The AM1 calculation produces a nearly symmetrical charge distribution about the water molecule. Bifurcated structures are typical results predicted by AM1 calculations. ${ }^{9-23}$ There are many experimental bifurcated structures reported in the literature, such as the helical conformation of cyclic oxyphosphoranes ${ }^{81}$ and DNA double helices. ${ }^{82}$ The problem with the AM1 bifurcated structure is the hydrogen bond angle of $108^{\circ}$, indicating that both lone pairs of electrons on the formaldehyde oxygen are involved in bonding.

One critical parameter responsible for structural differences calculated by PM3 and AM1 is the charge transfer from donor to acceptor molecules upon hydrogen bond formation. The symmetrical AMl global minimum 1a has a charge of -0.0023 on the donor water molecule and a charge of +0.0023 on the acceptor formaldehyde molecule; a charge transfer of 0.0023 occurs from the donor molecule to the acceptor molecule upon formation of the global minimum 1a. In the PM3 structure 1b, a charge transfer of 0.0246 from donor molecule to acceptor molecule occurs, an order of magnitude greater than occurs for the AM1 structure 1a. If structure 1a is used as the input geometry for a PM3 calculation, a local minimum with similar geometry to the AM1 structure results. This PM3 local minimum has two $\mathrm{H}-\mathrm{-}-\mathrm{O}$ distances of 2.65 and $2.77 \AA$ and two $\mathrm{O}-\mathrm{H}-\mathrm{-}-\mathrm{O}$ angles of 110.73 and $102.42^{\circ}$. The dissociation energy is -1.5 $\mathrm{kcal} \mathrm{mol} \mathrm{m}^{-1}$ and 0.0022 of charge is transferred from the donor molecule to the acceptor molecule, similar to the AM1 result for this symmetrical complex. When $\mathbf{1 b}$ is used as the input coordinates for an AM1 calculation, the AM1 global minimum $1 \mathrm{a}$ is the result.

To understand the differences between AM1 and PM3 hydrogen bonding geometries, the potential energy surface of the water dimer was explored with both methods. Two water molecules were oriented with the geometry shown by structure $\mathbf{2}$ in Figure 3 but with the O-- - H separation distance set at $99 \AA$. Unrestricted Hartree-Fock calculations were performed with PM3. In this reaction path calculation, the $\mathrm{O}-\mathrm{-}-\mathrm{H}$ separation distance was reduced and the geometry was optimized after each step. At $99 \AA$, there is no charge difference between the two hydrogens on the donating molecule (charge on each hydrogen equals 0.1793 ). At $4.0 \AA$, the hydrogen involved in hydrogen bonding has a charge of 0.1839 . In contrast, the donor water's remaining hydrogen has a charge of 0.1787 . Charge transfer between donor and acceptor begins when the $\mathrm{O}---\mathrm{H}$ separation distance reaches $3 \AA$. This charge transfer increases as intermolecular distance is reduced; when the global minimum structure 2 is reached, 0.0221 of charge is transferred from the donor water to the acceptor water. As the separation distance is decreased below $1.809 \AA$, charge transfer increases but repulsion drives up the overall energy of the system.

This same reaction path calculation was repeated with the AM1 method but with the PM3 hydrogen bond angle of $178.5^{\circ}$ held constant as the $\mathrm{O}-\mathrm{-H}$ distance was varied from 99 to $1 \AA$ (Fig. 2). The complex was geometry optimized at each step with the exception of the hydrogen bond angle, which was fixed at the PM3 global minimum (structure 2, Fig. 3), and the $\mathrm{O}-\mathrm{-}-\mathrm{H}$ step distance. In this calculation, a small amount of charge is transferred between the acceptor and donor water molecules. At the PM3 minimum geometry 2, the AM1 calculation shows a charge transfer of 0.0041 but in the opposite direction $(\mathrm{A} \rightarrow \mathrm{D})$ from the PM3 result $(\mathrm{D} \rightarrow \mathrm{A})$, that is, the donor water has a charge of +0.0041 and the acceptor water has a charge of -0.0041 , opposite in sign from the charge transfer that occurs in the PM3 and AM1 minimum structures. If the PM3 global minimum 2 is used as the input geometry for an AM1 calculation, a bifurcated complex similar to the water-formaldehyde complex $1 \mathrm{a}$ is the AM1 geometry-optimized result. These results suggest that the AM1 method does not reproduce classic hydrogen bonds because charge is transferred from the acceptor molecule to the donor molecule for dimers constrained to classic hydrogen bonding geometry. When hydrogen bond angle and bond distance constraints are relaxed in full AM1 optimizations of neutral complexes, bifurcated structures are inevitable results. We suggest the AM1 method is deficient in transferring charge both within the donor molecule and from the donor to the acceptor.

Our AM1 computed structures are the same as the structures reported by Dannenberg (I),$^{13}$ Ventura et al. (WW7), ${ }^{14}$ Rzepa and Yi (1b) ${ }^{9}$ and Smith et al. (7) ${ }^{35}$ There is virtually no charge transfer for the AM1 global minima, with just 0.0005 of the charge transferred from the donor to the acceptor. The AM1 structure is a transition state point on the high-level $a b$ initio potential energy surface. ${ }^{35,36}$ The AM1 minimum is actually a trifurcated structure, with three 
weak hydrogen bonds involving three lone pairs. This result led to the preliminary conclusion that AM1 overemphasizes hydrogen bond ability in such a way that the maximum number of lone pairs is involved in these bonds. ${ }^{14}$ Our results for 32 complexes confirm this conclusion for neutral species. One other structure for AM1 that is closest to the PM3 structure has an O-- - $\mathrm{H}$ distance of $2.1 \AA$ but is a second-order saddle point on the AM1 energy surface.

When the reaction path calculation is repeated with the PM3 method with the geometry fixed in the AM1 minimum, charge transfer occurs, although it is an order of magnitude less than occurs for the PM3 fully-optimized reaction path calculation. When the AM1 global minimum geometry is used as the input coordinates for a full optimization with PM3, a PM3 local minimum structure similar to the AM1 result is produced. This PM3 local minimum is symmetric, with $\mathrm{H}-\mathrm{-}-\mathrm{O}$ distances of $2.61 \AA$, O-H- - $\mathrm{O}$ angles of $104^{\circ}$, no charge transfer between the donor and acceptor molecules, and an association energy of $-2.0 \mathrm{kcal} \mathrm{mol}-1$.

The water/water system and the water/formaldehyde system illustrate that PM3 calculates hydrogen bonded complexes with charge transfer, or electron redistribution, between acceptor and donor molecules. AM1 calculations starting from the PM3 hydrogen bonded minima produce symmetrical bifurcated complexes with little if any charge transfer. PM3 calculations starting from the AM1 minima produce local minima similar to the symmetrical AM1 complexes; there is little charge transfer in these van der Waals complexes, which are local minima on the PM3 potential energy surfaces. These results reveal that if the calculated PM3 hydrogen bond energy has an absolute magnitude less than $2.0 \mathrm{kcal} \mathrm{mol}^{-1}$ care should be taken to explore the potential energy surface of the system in search of van der Waals complexes that are not hydrogen bonded. If a careful search is not made, then the location of the global minima is uncertain.

The MNDO/H method shows the same pattern of charge transfer as the PM3 method does for its successful description of hydrogen bonding between water dimers. ${ }^{83}$ The most stable, linear $\mathrm{MNDO} / \mathrm{H}$ dimer has a charge transfer of 0.02. For the less stable, bifurcated structure, only 0.002 units of charge are transferred.

AM1 calculations of the hydrogen bonded complexes displayed in Figures 3 and 4 reveal that AM1 predicts bifurcated complexes similar to 1a (Fig. 1). Only cyclic hydrogen bonded systems, such as the carboxylic acid dimers 12, 13, and 14, have angular geometries similar to $\mathrm{PM} 3$ results. Yet, the $\mathrm{O}-\mathrm{H}$ distances are greater than $2.2 \AA$. These AM1 hydrogen bond lengths for carboxylic acids are approximately $0.5 \AA$ greater than experimental and theoretical values. ${ }^{75,76}$ Our results confirm previous work that AM1 calculations are not reliable for determining intermolecular hydrogen bonded structures between neutral molecules. ${ }^{9,11,12,14,19,21,25,35}$

PM3 and AM1 calculations differ by the magnitude of charge transfer between donor and acceptor molecules in the complex. The global minima in AM1 calculations are bifurcated structures with symmetrical charge distributions. The AM1 global minima are local minima on the PM3 potential energy surfaces. The PM3 global minima are characterized by charge transfer of 0.02-0.06 units of charge for asymmetric hydrogen bonded complexes. For cyclic hydrogen bonded complexes, such as the carboxylic acid dimers 12-14, PM3 charge transfer is zero. Charge transfer occurs for these symmetric systems, but because each molecule is an acceptor and a donor the overall charge remains unchanged for the system. The ability of the PM3 method to predict hydrogen bonds is not correlated with the change in charge on the individual acceptor, donor, and hydrogen atoms upon formation of a complex. Rather, charge transfer between donor and acceptor molecules, or electron redistribution from the acceptor to the donor, is linked to the PM3 hydrogen bonded structures displayed in Figures 1-4.

\section{Differences between the MNDO Hamiltonians}

Why does the PM3 Hamiltonian treat hydrogen bonding better than the AM1 Hamiltonian? It is useful to examine the evolution of the semiempirical Hamiltonians pioneered by Dewar. ${ }^{1-4}$ MNDO overestimates repulsions between atoms separated by van der Waals distances. Thus, the MNDO minimized water dimer geometry reveals the underestimation of intermolecular forces by separating the waters by over $3.4 \AA$. In an attempt to overcome this problem, Dewar et al. modified the core repulsion function (CRF) by adding two to four parameterized Gaussian terms for each atom. ${ }^{3}$ The Gaussian parameters introduced into the AM1 Hamiltonian to modify the core-core repulsion between pairs of atoms are $K$, $L$, and $M$. The parameter $K$ determines the magnitude of the Gaussian term and whether the Gaussian is attractive or repulsive. The parameter $L$ determines the width of the Gaussian term and parameter $M$ determines the location of the Gaussian term. In AM1, a common value of $L$ was used for most atom types and this parameter was not optimized. Two strategies were used to modify the CRF and reduce excessive interatomic repulsions at large separations: (1) One or more attractive Gaussians were added, centered in the region where the repulsions were excessive; (2) repulsive Gaussians were centered at smaller internuclear separations to reduce the main term in the expression for core repulsion and reduce repulsion at larger internuclear distances. In the case of hydrogen and nitrogen, one attractive and two repulsive Gaussians were in- 
cluded. Two repulsive Gaussians were used for oxygen, with no attractive terms.

In the PM3 Hamiltonian, only two Gaussians are added per element. All three of the parameters $K, L$, and $M\left(a, b\right.$, and $c$ in Stewart's nomenclature $\left.{ }^{4}\right)$ are optimized within the PM3 framework. The elements hydrogen, nitrogen, and oxygen each have one attractive and one repulsive Gaussian term.

Energy partitioning was used to assess the differences in the two-center terms for MNDO, AM1, and PM3 calculations on the water dimer. The two-center terms are the resonance energy $(J)$, exchange energy $(K)$, electron-electron repulsion $(E-E)$, electron-nuclear attraction $(E-N)$, and nuclear-nuclear repulsion $(N-N)$. The Coulombic interaction is the sum of the repulsive and attractive terms $(C=E-E+$ $E-N+N-N$ ). PM3, AM1, and MNDO 1SCF calculations were performed on six different geometries: (1) the PM3 minimum geometry, structure 2; (2) the AMl second-order saddle point with an $\mathrm{O}-\mathrm{-}-\mathrm{H}$ distance of $2.1 \AA$; (3) the bifurcated minimum AM1 structure; (4) the MNDO minimum structure; and (5) two transition state structures from AM1 and MNDO calculations. In every case, the sum of the $E-E$ repulsion terms and the sum of the $N-N$ repulsion terms, as well as the sum of the $E-N$ attraction terms, had the greatest magnitudes for the PM3 calculations and the least magnitudes for AM1 calculations. Upon summing these terms to get the total electrostatic interaction $C, \mathrm{PM} 3$ had the lowest value, followed by AM1 and MNDO. For the six water structures examined, the value for $C$ ranged from $23.3-24.4 \mathrm{eV}$ for PM3, 27.0-28.5 eV for AM1, and 32.8-34.2 eV for MNDO. Only the $E-E, E-N$, and $N-N$ terms varied in these calculations; the values for $J, K$, and $C$ were approximately the same for a given Hamiltonian for all six different dimer geometries.

These two-center results reveal that while the AM1 Hamiltonian reduces the overall repulsive forces between atoms compared to MNDO the PM3 Hamiltonian further reduces the overall repulsive forces. The addition of parameterized Gaussian forces to the $\mathrm{CRF}$ was responsible for the reduction of repulsive forces within the AM1 framework. ${ }^{3}$ It is likely that the parameterization of the PM3 Hamiltonian, including the $K, L$, and $M$ parameters, is the reason why the PM3 Hamiltonian treats hydrogen bonding better than the AM1 Hamiltonian.

While the AM1 Hamiltonian appears to still overestimate repulsive forces, the PM3 Hamiltonian may reduce repulsive forces too much. This is evidenced by the PM3 predicted hydrogen bond lengths being $0.1-0.2 \AA$ shorter than the best high-resolution spectroscopy results in some cases. Additional evidence for this reasoning has appeared in a QCPE Bulletin [V. ßub, J. Messinger, and N. Heuser, QCPE Bull., 11(1), (1991)], where two methane monomers oriented with the two nearest $\mathrm{C}-\mathrm{H}$ bonds in a straight line reach a minimum at an $\mathrm{H}, \mathrm{H}$ separation distance of $1.72 \AA$. Success of the PM3 method in replicating geometries of hydrogen bonded complexes does not necessarily mean that other nonhydrogen bonded van der Waals complexes will be accurately reproduced by PM3 computations.

Stewart stated that the Gaussian core-core interactions that correct for long-range repulsion in AM1 and PM3 are operator equivalents to the van der Waals attraction or dispersion effects and can therefore behave as if they were dispersion forces operators. This allows correlation effects to be approximated by simple Gaussian functions at the MNDO level. ${ }^{4}$ Rzepa and Yi noted that the close agreement between PM3 and $a b$ initio correlated methods for hydrogen bonded complexes does suggest that the PM3 Hamiltonian must allow for certain types of correlation effects via the parameters. ${ }^{9}$ Further improvements in hydrogen bonding within the MNDO series of programs can be expected with the incorporation of high-resolution hydrogen bonded microwave structures and accurate heats of association for hydrogen bonded complexes in future parameterizations.

\section{Water Complexes and the PM3 Method}

Figure 3 includes the results of calculations for four water trimers, a pentamer, and a dimer. The dimer 2 has a hydrogen bond distance of $1.809 \AA$ and a hydrogen bond energy of $-3.55 \mathrm{kcal} \mathrm{mol}^{-1}$. The trimer 3 is an open trimer with the middle water serving both as an acceptor and donor. The open trimer 3 has bond angles near $160^{\circ}$ and a charge transfer of 0.0278 to the acceptor molecule. The charge on the middle water only changes by 0.0014 upon complex formation (Table III). This charge redistribution pattern suggests the donor molecule has transferred most of its charge through the open complex to the acceptor molecule. Two hydrogen bonds are formed in the open trimer; the distance between the closest hydrogen on the acceptor water and the oxygen on the original donor water is $2.6 \AA$.

Trimer 4 differs from 3 as each water in the cyclic trimer 4 is an acceptor and a donor; the cyclic trimer 4 has three bond angles of $145-149^{\circ}$; the hydrogen bond energy for the three bonds formed is -3.38 kcal mol-1. The cyclic trimer 4 is more stable than the open trimer 3 , with a heat of association of $-10.14 \mathrm{kcal} \mathrm{mol}^{-1}$ compared with $-9.04 \mathrm{kcal} \mathrm{mol}^{-1}$ for 3 .

To assess the relationship between hydrogen bond strength and charge transfer, trimers 5 and 6 were calculated and a pentamer 7 configured similar to the structure of ice. The trimer 5 has the central water donating to two different acceptors; 6 has one acceptor and two donor molecules. The energy per hydrogen bond is $0.35 \mathrm{kcal} \mathrm{mol}^{-1}$ greater for 6 than for $\mathbf{5}$, indicating that two donors and one acceptor 
is energetically more favorable than is one water donating its two hydrogens to two different acceptors. The most stable water trimer is the cyclic trimer (Table II), a result of formation of three bent hydrogen bonds. The sequential trimer $\mathbf{3}$, with two bent hydrogen bonds, is more stable than either of the complexes 5 or 6 , a result attributable to the greater polarizability of 3 , that is, in the open chain trimer 3 the interaction of the central water with an acceptor water leads to a redistribution of electron density that enhances the strength of the hydrogen bond with the third water molecule.

In the ice-like structure 7 , a central water molecule bonds to two different waters like 5 and accepts two different donors like 6 . The resulting structure is best described as the combination of two open trimers 3, with the central water in one trimer donating to an additional water with a bond angle of $156^{\circ}$ and accepting an additional water donor with a bond angle of $167^{\circ}$. The central water in the pentamer 7 has very little change in charge, with the charge transferred from the two outermost donors to the two outermost acceptors in the same manner as complex 3. An important point concerning water structures is that the charge transfer in the pentamer 7 increases for outer water molecules compared with isolated trimers 5 and 6 . The symmetrical configuration of the pentamer allows for more effective charge transfer, as more charge is available to be transferred among the molecules. The increase in polarity around the outermost waters in this small cluster $\mathbf{7}$ is quite likely the reason water clusters are favored; symmetrical clusters yield more and stronger hydrogen bonds. The hydrogen bond energy is greatest for the water systems described here when the charge is transferred across a central molecule that is both an acceptor and donor.

The charge transfer results for the water dimer and the ice-like structure 7 are very similar to the results obtained with the $\mathrm{MNDO} / \mathrm{H}$ method. ${ }^{83}$ The experimental enthalpy of formation for the hydrogen bond in water ranges from -4.4 to $-5.4 \mathrm{kcal} \mathrm{mol}^{-1}$ (Table III). The PM3 result that the hydrogen bond energy is $-4.5 \mathrm{kcal} \mathrm{mol}^{-1}$ for complexes 3 and 7 agrees with experiment. The results of the PM3 calculations on these small water clusters illustrate that the PM3 method is capable of predicting both linear and bent hydrogen bonds.

Two previous evaluations of water cluster geometries from $\mathrm{AM} 1$ calculations reveal that $\mathrm{AM} 1$ retains the incorrect features of the bifurcated dimer in cyclic oligomers of water. ${ }^{9,12}$ These authors mention that AM1 calculations can yield hydrogen bond energies close to known values for geometries where a semblance of the hydrogen bond is difficult to discern. ${ }^{9,12,18}$ Our AM1 results for 32 intermolecular structures confirm this view, as AMl-calculated energies appear reasonable yet geometries do not. Because the geometries are not reasonable, we do not report the AM1 energetic results in Tables II and III.

\section{Types of Hydrogen Bonds}

$\mathrm{O}-\mathrm{H}-\mathrm{-O}$

Complexes 1b, 2-7, and 8-14 are displayed in Figures 1, 3, and 4. Pertinent information for the O-H- - -O hydrogen bond type appears in Table III. The PM3 results for the water complexes 2-7 were discussed in the previous section. Comparison of these PM3 results with experimental and $a b$ initio work is discussed here.

Rzepa and Yi previously reported the PM3 structures for a water dimer, trimer, and tetramer. ${ }^{9}$ Their dimer and trimer are identical to our dimer 2 and cyclic trimer 4. The trans-linear structure of the dimer 2 agrees with previous calculations $s^{4,9,69,84}$ and molecular beam resonance and microwave spectroscopy experiments. ${ }^{28-32}$ Rigorous ab initio calculations replicate the details of the water dimer geometry with greater fidelity. ${ }^{33-36} A b$ initio calculations $^{69}$ and simulated annealing computations $\mathrm{s}^{85}$ predict that the cyclic water trimer is the most stable triplex, followed by the open sequential trimer 3, and then by the double donor and acceptor complexes, in agreement with our results (Table II). The $a b$ initio results were explained by the effects of stabilizing and destabilizing three-body interactions. Polarization makes 3 the strongest of the open dimers, but polarization of the double donor 5 and double acceptor 6 complexes leads to mutual weakening of the hydrogen bonds. ${ }^{69}$ This argument is supported by the PM3 calculations as explained in the preceding section.

Rzepa and Yi also observed this polarization effect in their PM3 calculations of a water dimer, cyclic trimer, and cyclic tetramer. ${ }^{9}$ In their system, the hydrogen bond strength increases as waters are added to the cluster, which they trace to the increased polarization of the water molecule upon hydrogen bond formation. Structural evidence for a cyclic hydrogen bonded trimer comes from the measured rotational constants of 1-naphthol-(water) clusters $^{86}$ The infrared spectra of several isotopomers of the water trimer have been studied in argon and krypton matrices. ${ }^{87}$ The results indicate the trimer is cyclic. Thus, the PM3 calculations successfully predict the correct geometries for the experimentally determined water dimer $^{28-32}$ and trimer. ${ }^{86,87}$

In the ice-like structure 7, all three kinds of trimer substructures are present, resulting in partial compensation of repulsive three-body interactions; consequently, PM3 predicts hydrogen bond energies as strong as the open trimer for the cluster 7. Structure 7 is one of many possible minima on the water pentamer potential energy surface. The choice of this structure was based upon the desire to better understand factors involved in PM3 calculations. There 
are many possible configurations of water pentamers. A theoretical study of water clusters, from dimers to hexamers, was done with the QPEN/B2 potential function. ${ }^{88}$ Eleven local minima were found on the pentamer potential energy surface; the global minimum was a cyclic pentamer containing five hydrogen bonds. In contrast, the simulated annealing method produces a structure with four other molecules arranged tetrahedrally around the central water. ${ }^{85}$ Our PM3 results for water trimers support the prediction ${ }^{88}$ that the cyclic cluster with five hydrogen bonds is the most stable pentamer.

The water/methanol complex 8, methanol dimer 10 , and the methanol/water complex 11 have similar hydrogen bond energies, charge transfer properties, and hydrogen bond angles. The methanol dimer has the weakest hydrogen bond, followed by the water/ methanol complex and the methanol/water complex. These results, along with those for the water dimer, indicate that the water molecule is superior to methanol both as an acceptor and donor.

The formic acid dimer 12, acetic acid dimer 13, and benzoic acid dimer 14 are cyclic structures incorporating two hydrogen bonds. Each hydrogen bond contributes approximately $4.5 \mathrm{kcal} \mathrm{mol}^{-1}$ to stabilization of these carboxylic acid complexes. The formic acid dimer is symmetric, with hydrogen bonds of $1.776 \AA$ and hydrogen bond angles of $177.4^{\circ}$. The PM3 hydrogen bond energy is $-4.34 \mathrm{kcal} \mathrm{mol}^{-1}$, in reasonable agreement with a recent Fourier transform infrared (FTIR) experiment ${ }^{71}$ that yielded a bond energy of $-5.85 \mathrm{kcal} \mathrm{mol}^{-1}$. The structure of the formic acid dimer has been investigated with gas electron diffraction techniques. ${ }^{75}$ Numerous $a b$ initio calculations have been performed, with a computation at the double- $\zeta$ plus polarization level $(D Z+P)$ in excellent agreement with experimental results. ${ }^{76}$ Table IV compares experimental $D Z+P$, and present results for the formic acid dimer. The PM3 geometry agrees with the experimental and high-level $a b$ initio results. The authors of the $D Z$ $+P a b$ initio calculation assert that the experimental $\mathrm{O}-\mathrm{H}$ single bond distance and the $\mathrm{H}-\mathrm{C}=\mathrm{O}$ bond angle values are in error by an amount greater than the estimated experimental uncertainty. ${ }^{76}$ The PM3 results listed in Table IV support the argument that the experimental $\mathrm{O}-\mathrm{H}$ bond distance and $\mathrm{H}$ $\mathrm{C}=\mathrm{O}$ bond angle are outside the range of uncertainty reported in the gas diffraction experiment.

The acetic acid dimer 13 (Fig. 4) is similar to the formic acid complex. The calculated PM3 hydrogen bond energy of $-4.52 \mathrm{kcal} \mathrm{mol}^{-1}$ is approximately the same as the hydrogen bond energy of formic acid (Table III). The structures of the acetic acid monomer and dimer have been determined by gas electron diffraction. ${ }^{89}$ The experimental values for $\mathrm{C}-\mathrm{C}$, $\mathrm{C}=\mathrm{O}, \mathrm{C}-\mathrm{O}$, and $\mathrm{C}-\mathrm{H}$ bond distances in the dimer are $1.506,1.231,1.334$, and $1.102 \AA$, respectively. The PM3 structure has bond distances of $1.500,1.228$,
1.338 , and $1.098 \AA$, respectively, well within one standard deviation of the experimental values. The $\mathrm{C}-\mathrm{C}=\mathrm{O}$ and C-C-O experimentally determined bond angles of 123.6 and $113.0^{\circ}$ compare well with the PM3 results of 126.8 and $115.7^{\circ}$. The acceptor oxygen/ donor oxygen separation distance is $2.68 \AA$ from the gas diffraction work, and the present calculation yields a value of $2.74 \AA$ for this parameter. The benzoic acid dimer 14 is another symmetrical carboxylic acid complex, with a calculated hydrogen bond energy of $-4.38 \mathrm{kcal} \mathrm{mol}^{-1}$. The experimental value ${ }^{73}$ obtained from electron diffraction work in 1969 is $-7.3 \mathrm{kcal} \mathrm{mol}^{-1}$, and in general experimental hydrogen bond energies for carboxylic acids range from -6 to $-7 \mathrm{kcal} \mathrm{mol}^{-1} .^{90}$ All three of the carboxylic acid dimers exhibit symmetrical charge transfer, as each molecule is both a hydrogen donor and hydrogen acceptor, and the hydrogen bonds that form are quite strong.

The water/carbon dioxide complex 9 has a small association energy of $-0.97 \mathrm{kcal} \mathrm{mol}^{-1}$ and a relatively small amount of charge transfer, with 0.0151 units of charge transferred from water to carbon dioxide upon complex formation. The complex 9 is not experimentally observed. High-resolution spectroscopy results show that the water/carbon dioxide complex is a planar, $C_{2 \mathrm{v}}$ structure, with the oxygen atom $2.836 \AA$ from the carbon and the water hydrogens pointing away from $\mathrm{CO}_{2}{ }^{91,92}$ The $\mathrm{O}-\mathrm{H}-\mathrm{-}-\mathrm{O}$ bond in the water/formaldehyde complex $\mathbf{1 b}$ is stronger than in the symmetrical $\mathrm{CO}_{2}$ molecule, with 0.0246 charge transferred to water and a calculated energy of $-2.75 \mathrm{kcal} \mathrm{mol}^{-1}$. The PM3 structure $1 \mathbf{b}$ differs from the strongly bent structure calculated by SCF, MPZ, and CEPA-1 ab initio calculations. ${ }^{84}$ High-resolution spectroscopy experiments for the water/formaldehyde system would be useful for comparing these theoretical results.

Because the water/carbon dioxide complex global minima ${ }^{91,92}$ is a van der Waals complex with no hydrogen bonding, the PM3 structure, with a hydrogen bond energy of approximately $1 \mathrm{kcal} \mathrm{mol}^{-1}$, is only a local minima. Therefore, when PM3 predicts a hydrogen bond energy with an absolute magnitude less than $2 \mathrm{kcal} \mathrm{mol}^{-1}$ other van der Waals complexes should be examined to ensure determination of the global minimum.

\section{$N-H-\cdots$}

Ammonia is the only first-row hydride that does not donate a hydrogen to form a hydrogen bonded complex with ammonia. ${ }^{93}$ High-resolution microwave spectroscopy experiments ${ }^{93}$ of van der Waals complexes of $\mathrm{NH}_{3}$ isotopomers reveal that the gas-phase ammonia dimer complex has a distance of $3.337 \AA$ separating the nitrogen atoms. Although the positions of the six hydrogen atoms are not exactly 
known, none of the allowed structures may be described as hydrogen bonded. The dissociation energy of this complex is less than $2.8 \mathrm{kcal} \mathrm{mol}^{-1}$ according to microwave-infrared double resonance studies. ${ }^{91}$ The calculated PM3 ammonia dimer 15, displayed in Figure 4, is unique among investigated complexes because a positive energy is required for the formation of the classic ammonia dimer hydrogen bond. Eigenvalue calculations show that $\mathbf{1 5}$ is a local minimum even though the complex requires $0.19 \mathrm{kcal}$ $\mathrm{mol}^{-1}$ more energy than two monomers separated by infinite distance. Therefore, the ammonia dimer $\mathbf{1 5}$ is not held together by a hydrogen bond.

Unrestricted Hartree--Fock calculations of the $\mathrm{NH}_{3} / \mathrm{NH}_{3}$ system reveal that the potential energy hypersurface is extremely flat with numerous local minima. The lowest-energy PM3 structure is displayed at the bottom right in Figure 4. This van der Waals complex is not hydrogen bonded, with an enthalpy of association of $-0.93 \mathrm{kcal} \mathrm{mol}^{-1}$ and a $\mathrm{N}$ - - $\mathrm{N}$ separation distance of $3.5 \AA$. The molecular mechanics for clusters approach has been applied to complexes of ammonia, yielding a dimer structure consistent with our results. ${ }^{94}$ Determination of the exact structure of the ammonia dimer is the subject of ongoing research in high-resolution spectroscopy ${ }^{95,96}$

Calculation of the $\mathrm{NH}_{3} / \mathrm{NH}_{3}$ dimer using the $6-31+\mathrm{G}(d)$ basis set, followed by evaluation of the energetics of the stationary points using fully polarized 6-31 + $\mathrm{G}(d, p)$ basis sets, predicts the traditional ammonia hydrogen bond. ${ }^{97}$ This ab initio calculation, which included electron correlation using fourth-order Møller-Plesset perturbation theory (MP4), yields a structure similar to the water dimer, with a dimerization energy of $-3.3 \mathrm{kcal} \mathrm{mol}^{-1}$. Reoptimizing the geometries at the MP2/6-311 + G(d,p) level does not change the $a b$ initio prediction of the ammonia dimer ${ }^{98} \mathrm{Ab}$ initio calculations at the 6$31 \mathrm{G}(d)$ leve ${ }^{99}$ and modified $6-31 \mathrm{G}^{* *}$ leve $\mathrm{l}^{100}$ predict a cyclic structure with $C_{2 h}$ symmetry and an enthalpy of association of $-1.6 \mathrm{kcal} \mathrm{mol}^{-1}$. The separation distance between the nitrogens is $3.271 \AA$ in this calculation and the structure is not hydrogen bonded. No ammonia dimer structure calculated by quantum-mechanical techniques is consistent with the experimental results, and only some $a b$ initio structures ${ }^{99,100}$ and the PM3 structure are close.

The dimethylamine/ammonia complex 16 was calculated to help assess the effects of electron donating groups on $\mathrm{N}-\mathrm{H}--\mathrm{N}$ hydrogen bonds. The $\mathrm{C}_{2} \mathrm{H}_{7} \mathrm{~N}$ molecule is slightly better than $\mathrm{NH}_{3}$ as a donor, but the effect is small, with a PM3-calculated hydrogen bond energy of $-0.07 \mathrm{kcal} \mathrm{mol}^{-1}$. A hydrogen bonded complex would not be expected to predominate over other van der Waals complexes in the gas phase. Although the ammonia nitrogen is not a donor, nitrogens in rings are capable of donating hydrogen bonds. The pyrazole trimer 17 is a sym- metrical complex containing three strong hydrogen bonds, with an energy of $-4.92 \mathrm{kcal} \mathrm{mol}^{-1}$ per bond.

\section{$O-H--N$}

The water/pyridine complex 18 and the methanol/ pyridine complex 19 have similar donor-acceptor distances, charge transfer properties, and hydrogen bond energies. These structures are displayed in Figure 4 and results are presented in Tables II and III. The water/pyridine dimer has a stronger calculated hydrogen bond and a shorter hydrogen bond length than the methanol/pyridine dimer.

Ammonia is an excellent hydrogen bond acceptor. The complexes of water $\mathbf{2 0}$ and methanol $\mathbf{2 1}$ with ammonia have similar bond strengths, charge transfer properties, and hydrogen bond lengths. Structural analysis of a molecular beam electric resonance spectroscopy experiment ${ }^{87}$ yielded a geometry for the $\mathrm{H}_{2} \mathrm{O} / \mathrm{NH}_{3}$ complex similar to the PM3 structure 20, with a linear $\mathrm{O}-\mathrm{H}--\mathrm{N}$ bond. The PM3 calculated hydrogen bond energy of $3.03 \mathrm{kcal} \mathrm{mol}^{-1}$ is lower than the $5.6 \mathrm{kcal} \mathrm{mol}^{-1}$ energy calculated with a modified $6-31 \mathrm{G}^{* *}$ basis set. ${ }^{100}$ The experimental donor atom/acceptor atom distance is $2.983 \AA, 0.19 \AA$ longer than the result from the PM3 calculation; the experimental $\mathrm{H}$ - - - N distance is $1.97 \AA$ and the PM3 value is $1.825 \AA$. Ab initio calculations agree better with the experimental hydrogen bond length. ${ }^{97-99}$

The methanol/ammonia complex 21 has been studied experimentally with a pulsed-nozzle Fouriertransform microwave spectrometer ${ }^{101}$ Data analysis yields a hydrogen bond length of $2,015 \AA$ and a bond angle of $179.93^{\circ}$, with the experimental work ${ }^{87,101}$ for 20 and 21 agreeing closely just as the present PM3 results agree closely for these similar systems. It is apparent that a weakness in the PM3 method is the underestimation of the hydrogen bond length in these complexes, on the order of $0.1-0.2 \AA$. The experimental work indicates that the water/ammonia complex 20 has a slightly stronger interaction than the methanol/ammonia complex 21 . This trend is also indicated by the present results, with the PM3 hydrogen bond energy $0.2 \mathrm{kcal} \mathrm{mol}^{-1}$ greater and the hydrogen bond length $0.002 \AA$ shorter for 20 . Complexes 18-21 reinforce the idea stated previously: The water molecule is a better donor than methanol.

The complexes of formic acid $\mathbf{2 2}$ and acetic acid 23 with ammonia, although having similar charge transfer and bond lengths, differ greatly in bond strength. The $\mathrm{HCOOH} / \mathrm{NH}_{3}$ complex 22 has a hydrogen bond energy of $-0.79 \mathrm{kcal} \mathrm{mol}^{-1}$ and the $\mathrm{CH}_{3} \mathrm{COOH} / \mathrm{NH}_{3}$ complex 23 has a bond energy of $-2.5 \mathrm{kcal} \mathrm{mol}^{-1}$. Based on the low calculated hydrogen bond energy, other van der Waals complexes of $\mathrm{HCOOH} / \mathrm{NH}_{3}$ are expected to predominate in the gas phase. It is clear from the analysis of PM3 hydrogen bonded complexes that although charge transfer from the donor to the acceptor molecule is 
a general indicator of hydrogen bond strength there are other factors involved in the subleties of the PM3 calculation. Complex $\mathbf{2 2}$ has one of the highest values for charge transfer yet one of the weakest calculated hydrogen bonds.

\section{$\mathrm{N}-\mathrm{H}_{-}^{--} \mathrm{O}$}

Complexes 24-28 are displayed in Figure 4 and results are presented in Tables II and III. The fairly symmetrical formamide dimer $\mathbf{2 4}$ has a hydrogen bond energy of $-2.34 \mathrm{kcal} \mathrm{mol}^{-1}$ per bond, as calculated with the PM3 method, and the experimental value derived from sublimation energies is $-7 \mathrm{kcal}$ mol $^{-1}$. The pyridone dimer 25 has two strong calculated hydrogen bonds with an energy of -4.92 $\mathrm{kcal} \mathrm{mol}^{-1}$ per bond. The ammonia/water complex 26 and the ammonia/methanol complex 27 have a charge transfer of 0.0130 and 0.0137 units of charge, respectively, to the water and methanol. These complexes form weak hydrogen bonds of -0.87 and $-0.21 \mathrm{kcal} \mathrm{mol}^{-1}$, respectively. These results reinforce the notion that water is a better hydrogen bond acceptor than methanol.

The $\mathrm{NH}_{3} / \mathrm{HCOOH}$ complex 28 transfers 0.0178 units of charge from ammonia to formic acid and forms a weak hydrogen bond ( $\left.-0.43 \mathrm{kcal} \mathrm{mol}^{-1}\right)$. These calculations illustrate a fundamental result; PM3 predicts ammonia is a poor hydrogen donor (structures 15, 26-28, and 32; see Table III). These results agree with the conclusions of Nelson et al., ${ }^{94}$ that $\mathrm{NH}_{3}$ is a strong acceptor and poor donor, contrary to the traditional picture of $\mathrm{NH}_{3}$ as a strong donor. None of the ammonia complexes where $\mathrm{NH}_{3}$ is a donor $(\mathbf{1 5}, \mathbf{2 6 - 2 8}, \mathbf{3 2})$ should predominate among the possible van der Waals complexes based upon their small calculated PM3 hydrogen bond energies.

A previous PM3 study of the ammonia/formaldehyde system resulted in two unusual structures, with association energies of -0.08 and $-1.0 \mathrm{kcal} \mathrm{mol}^{-1}$. These structures did not agree with those from $a b$ initio calculations (MP2/6-31G** level) and the authors cite a specific error in the PM3 method; namely, the interaction between $\mathrm{N}-\mathrm{H} \sigma$-bonds and an oxygen lone pair of electrons. ${ }^{9}$ These authors point out that the reported ${ }^{4} \mathrm{PM} 3$ values for the atomic valence ionization potentials $U_{s s}$ and $U_{p p}$ for nitrogen are approximately 12 and $14 \mathrm{eV}$ less negative than expected from a smooth interpolation of the parameters from boron to fluorine. This potential error in $U_{s s}$ and $U_{p p}$ for nitrogen would lead to a less electronegative nitrogen center than expected and could affect properties where the $s / p$ orbital mixing at nitrogen changes (such as the inversion barrier in ammonia and the rotational barrier for the $\mathrm{C}-\mathrm{N}$ peptide bond). ${ }^{9}$ While the $U_{s s}$ and $U_{p p}$ values may affect some aspects of PM3 calculations on nitrogen-containing compounds, ${ }^{50}$ they do not appear to be a factor in hydrogen bonding as PM3 is far superior to $\mathrm{AM} 1$ in predicting hydrogen bonding complexes involving nitrogen. Rzepa and $\mathrm{Yi}$ noted that a partitioning of the two-center energies reveals that the total O- - $\mathrm{H}$ term for ammonia donating a hydrogen to formaldehyde is significantly less than for the complexes where water is the donor molecule. ${ }^{9}$ This result is additional evidence that the PM3 parameterization of the Gaussian core-core interactions are adequate dispersion forces operators because PM3 calculations correctly predict that ammonia is a poor hydrogen bond donor.

\section{Hydrogen Bonds Involving Fluorine}

The complexes involved in hydrogen bonding with HF are displayed in Figure 4 and results summarized in Tables II and III. The $\mathrm{H}_{2} \mathrm{O} / \mathrm{HF}$ complex 29 and the $\mathrm{HF} / \mathrm{H}_{2} \mathrm{O}$ complex 30 illustrate that $\mathrm{HF}$ is a better donor to oxygen $\left(-5.51 \mathrm{kcal} \mathrm{mol}^{-1}\right)$ than $\mathrm{OH}$ is to fluorine $\left(-4.02 \mathrm{kcal} \mathrm{mol}^{-1}\right)$, in accordance with standard discussions of hydrogen bond strengths. ${ }^{66,67}$ The experimental value is $-7.2 \mathrm{kcal} \mathrm{mol}^{-1}$ for the $\mathrm{HF} / \mathrm{H}_{2} \mathrm{O}$ complex and the experimental donor/acceptor distance is $2.662 \AA$; the PM3 values are -5.51 $\mathrm{kcal} \mathrm{mol}^{-1}$ and $2.68 \AA$. Both the experimental ${ }^{102}$ and PM3 geometries have $C_{s}$ symmetry. The $\mathrm{HF} / \mathrm{NH}_{3}$ complex 31 has a hydrogen bond energy of -5.92 kcal $\mathrm{mol}^{-1}$, and the $\mathrm{NH}_{3} / \mathrm{HF}$ complex 32 has a hydrogen bond energy of $-1.50 \mathrm{kcal} \mathrm{mol}^{-1}$. The PM3 results predict complex $\mathbf{3 1}$ should be observed in the gas phase, and we would expect only to observe HF donating to ammonia. These four structures $\mathbf{2 9}$ 32 follow the traditionally recognized principle that the acceptor strength follows the order $\mathrm{N}>$ $\mathrm{O}>\mathrm{F}$ and the donor strength follows the order $\mathrm{F}>\mathrm{O}>\mathrm{N}$.

\section{CONCLUSIONS}

The PM3 semiempirical quantum-mechanical method successfully predicts intermolecular hydrogen bonding between neutral molecules. One main difference between AM1, which does not describe intermolecular hydrogen bonding between neutral molecules, and PM3 is that in the PM3 calculations significant charge transfer occurs from donor to acceptor molecules. The magnitude of charge transfer is on the order of 0.02-0.06 units of charge when strong hydrogen bonds are formed. Other van der Waals complexes computed with PM3, and all complexes calculated with AM1, do not show such a large redistribution of electronic charge.

PM3 is predictive; calculated hydrogen bond energies greater than an absolute magnitude of $2 \mathrm{kcal}$ $\mathrm{mol}^{-1}$ suggest that the global minima is a hydrogen bonded complex; energies less than an absolute magnitude of $2 \mathrm{kcal} \mathrm{mol}^{-1}$ imply that other van der Waals 
complexes will be observed experimentally. The water/carbon dioxide system $\mathbf{9}$, ammonia/ammonia system 15, ammonia/water system 26, ammonia/ methanol system 27, and the ammonia/hydrogen fluoride system $\mathbf{3 2}$ have PM3 energies less than an absolute magnitude of $1.6 \mathrm{kcal} \mathrm{mol}^{-1}$ and are not experimentally observed. The dimethylamine/ammonia complex 16, formic acid/ammonia complex $\mathbf{2 2}$, and ammonia/formic acid complex 28 are predicted to be less stable than other van der Waals complexes, as the PM3 hydrogen bond energies are less than an absolute magnitude of $0.8 \mathrm{kcal} \mathrm{mol}^{-1}$.

Compared with experimental heats of association, PM3 calculations underestimate reliable experimental information by approximately $1-2 \mathrm{kcal} \mathrm{mol}^{-1}$. Accurate experimental heats of association are difficult to obtain, and further work in this area is encouraged.

The geometries of the PM3 hydrogen bonded complexes agree with high-resolution spectroscopy and gas electron diffraction data, as well as with highlevel $a b$ initio calculations. Agreement between experimental hydrogen bond geometries and PM3 hydrogen bond geometries is excellent for the cyclic carboxylic acid systems. A weakness in the PM3 method is the underestimation of hydrogen bond lengths by $0.1-0.2 \AA$ for some systems. This problem causes the acceptor/donor distances to be underestimated by an equal amount.

The PM3 calculations are sensitive to the shallow potential energy surfaces of these weak interactions. Both PM3 and experimental results agree that ammonia is an excellent hydrogen bond acceptor and a terrible hydrogen bond donor. Electronegativity differences between $\mathrm{F}, \mathrm{N}$, and $\mathrm{O}$ predict that donor strength follows the order $\mathrm{F}>\mathrm{O}>\mathrm{N}$; acceptor strength follows the order $\mathrm{N}>\mathrm{O}>\mathrm{F}$. PM3 mirrors these electronegativity differences in the calculations, predicting the F-H- - $\mathrm{N}$ bond to be the strongest and the $\mathrm{N}-\mathrm{H}--\mathrm{F}$ bond the weakest. PM3 results predict water is a better hydrogen bond donor and acceptor than is methanol.

The PM3 Hamiltonian treats intermolecular hydrogen bonding between neutral molecules better than the AM1 Hamiltonian, in part because the PM3 parameterization results in a reduction of two-center repulsive forces in the CRF. The ability of the PM3 method to model intermolecular hydrogen bonding means reasonably accurate quantum-mechanical calculations can be applied to small biologic systems. In fact, since the completion of this work Kollman and coworkers reported that PM3 is superior to AM1 for modeling compounds pertinent to the serine protease catalyzed hydrolysis of amides and esters. ${ }^{103}$ These same researchers used the PM3 method to show that the attack of the substrate by the active site serine to form a tetrahedral intermediate was the rate-limiting step with both substrates. ${ }^{104} \mathrm{We}$ an- ticipate additional results pertinent to biochemistry from PM3 computations and expect that future parameterizations of the modified NDDO method will improve the accuracy of hydrogen bond calculations.

This work was supported by Lake Forest College (M.W.J.) and a Bristol-Meyers Company Grant of Research Corporation (G.C.S.). The research reported here was completed as part of the Honors Senior Thesis in Chemistry for M.W.J., which won the 1991 Phi Beta Kappa Senior Thesis Award at Lake Forest College. The authors thank David Pilkington and Tricia Lively for technical assistance and the referees for helpful comments.

\section{References}

1. R.C. Bingham, M.J.S. Dewar, and D.H. Lo, J. Am. Chem. Soc., 97, 1285, 1294, 1302, 1307 (1975).

2. M.J.S. Dewar and W. Thiel, J. Am. Chem. Soc., 99, 4899, 4907 (1977)

3. M.J.S. Dewar, E.G. Zoebisch, E.F. Healy, and J.J.P. Stewart, J. Am. Chem. Soc., 107, 3902 (1985).

4. J.J.P. Stewart, J. Comp. Chem., 10, 209, 221 (1989).

5. F.L. Pilar, Elementary Quantum Chemistry, McGraw-Hill, New York, 1990.

6. D.M. Hirst, A Computational Approach to Chemistry, Blackwell Scientific Publications, Oxford, UK, 1990.

7. J.J.P.Stewart, QCPE 455, Department of Chemistry, Indiana University, Bloomington, IN.

8. J.J.P. Stewart, J. Comp. Chem., 11, 543 (1990).

9. H.S. Rzepa and M. Yi, J. Chem. Soc., Perkins Trans. 2, 943 (1990).

10. I.H. Williams, J. Am. Chem. Soc., 109, 6299 (1987).

11. A.A. Bliznyuk and A.A. Voityuk, J. Mol. Struct. (THEOCHEM), 164, 343 (1988).

12. W.C. Herndon and T.P. Radhakrishnan, Chem. Phys. Lett., 148, 492 (1988).

13. J.J. Dannenberg, J. Phys. Chem., 92, 6869 (1988).

14. O.N. Ventura, E.L. Coitiño, A. Lledós, and J. Bertrán, J. Mol. Struct. (THEOCHEM), 187, 55 (1989).

15. J.Y. Choi, E.R. Davidson, and I. Lee, J. Comp. Chem., 10, 163 (1989).

16. J.J. Dannenberg and L.K. Vinson, J. Phys. Chem., 92, 5635 (1988).

17. L.K. Vinson and J.J. Dannenberg, J. Am. Chem. Soc., 111, 2777 (1989).

18. S. Galera, J.M. Lluch, A. Oliva, and J. Bertrán, J. Mol. Struct. (THEOCHEM), 163, 101 (1988).

19. I. Juranic, H.S. Rzepa, and M. Yi, J. Chem. Soc., Perkin Trans. 2, 877 (1990).

20. C.H. Reynolds, J. Am. Chem. Soc, 112, 7903 (1990).

21. M. Khalil, R.J. Woods, D.F. Weaver, and V.H. Smith, J. Comp. Chem., 12, 584 (1991).

22. T. Katagi, J. Comp. Chem., 11, 1094 (1990).

23. L.P. Davis, L.W. Burggraf, and D.M. Storch, J. Comp. Chem., 12, 350 (1991).

24. G. Buemi, F. Zuccarello, and A. Raudino, J. Mol. Struct. (THEOCHEM), 164, 379 (1988).

25. H.S. Rzepa and M. Yi, J. Chem. Soc., Faraday Trans. 2, 531 (1991).

26. P.L. Cummins and J.E. Gready, J. Comp. Chem., 11, 791 (1990).

27. G.P. Ford and B. Wang, J. Comp. Chem., 13, 229 (1992).

28. T.R. Dyke, J. Chem. Phys., 66, 492 (1977).

29. T.R. Dyke, K.M. Mack, and J.S. Muenter, J. Chem. Phys., 66, 498 (1977). 
30. J.A. Odutola and T.R. Dyke, J. Chem. Phys., 72, 5062 (1980).

31. L.H. Coudert, F.J. Lovas, R.D. Suenram, and J.T. Hougen, J. Chem. Phys., 87, 6290 (1987).

32. J.A. Odutola, T.A. Hu, D. Prinslow, S.E. O'dell, and T.R. Dyke, J. Chem. Phys., 88, 5352 (1988).

33. Z. Latajka, H. Ratajczak, and W.B. Person, J. Mol. Struct., 194, 89 (1989).

34. P. Herbine and T.R. Dyke, J. Chem. Phys., 83, 3768 (1985).

35. B.J. Smith, D.J. Swanton, J.A. Pople, H.F. Schaefer, and L. Radom, J. Chem. Phys., 92, 1240 (1990).

36. C.J. Marsden, B.J. Smith, J.A. Pople, H.F. Schaefer, and L. Radom, J. Chem. Phys., 95, 1825 (1991).

37. E.S. Marcos, J.J. Maraver, J.L. Chiara, and A. GómezSánchez, I. Chem. Soc., Perkin Trans. II, 2059 (1988).

38. G. Buemi and C. Gandolfo, J. Chem. Soc., Faraday Trans. 2, 85, 215 (1989).

39. G. Buemi, J. Chem. Soc., Faraday Trans. 2, 85, 1771 (1989).

40. S. Millefiori and A. Millefiori, J. Chem. Soc., Faraday Trans. 2, 85, 1465 (1989).

41. G. Buemi, J. Chem. Soc., Faraday Trans. 2, 86, 2813 (1990).

42. G. Buemi, J. Mol. Struct. (THEOCHEM), 201, 193 (1989).

43. W.M.F. Fabian, J. Phys. Org. Chem., 3, 332 (1990).

44. G. Buemi and F. Zuccarello, J. Mol. Struct. (THEOCHEM), 209, 89 (1990).

45. R.J. Woods, W.A. Szarek, and V.H. Smith, J. Am. Chem. Soc., 112, 4732 (1990).

46. J.J. Novoa and M.-H. Whangbo, J. Am. Chem. Soc., 113, 9017 (1991).

47. G. Buemi, J. Mol. Struct. (THEOCHEM), 208, 253 (1990).

48. R. Voets, J.-P. Francois, J.M.L. Martin, J. Mullens, J. Yperman, and L.C. Van Pouke, J. Comp. Chem., 10, 449 (1989).

49. R. Voets, J.-P. Francois, J.M.L. Martin, J. Mullens, J. Yperman, and L.C. Van Pouke, J. Comp. Chem., 11, 269 (1990).

50. M. Szafran and J. Koput, J. Comp. Chem., 12, 675 (1991)

51. R. Karaman, J.-T.L. Huang, and J.L. Fry, J. Comp. Chem., 11, 1009 (1990).

52. R. Karaman, J.-T.L. Huang, and J.L. Fry, J. Comp. Chem., 12, 536 (1991).

53. P. Camilleri, C.A. Marby, B. Odell, H.S. Rzepa, R.N. Sheppard, J.J.P. Stewart, and D.J. Williams, J. Chem. Soc., Chem. Commun., 1772 (1989).

54. O.N. Ventura, E.L. Coitiño, K. Irving, A. Iglesias, and A. Lledós, J. Mol. Struct. (THEOCHEM), 210, 427 (1990).

55. D.M. Seeger, C. Korzeniewski, and W. Kowalchyk, $J$. Phys. Chem., 95, 6871 (1991).

56. M.B. Coolidge, J.E. Marlin, and J.J.P. Stewart, J. Comp. Chem., 12, 948 (1991).

57. P.-O. Ástrand, A. Wallquist, and G.J. Karlström, J. Phys. Chem., 95, 6395 (1991); J.J. Dannenberg and M. Mezei, J. Phys. Chem., 95, 6396 (1991).

58. S. Tolosa, J.J. Esperilla, and F.J. Olivares del Valle, $J$. Comp. Chem., 11, 576 (1990).

59. S.K. Loushin and C.E. Dykstra, J. Comp. Chem., 8, $81(1987)$.

60. S.K. Loushin, S.-Y. Liu, and C.E. Dykstra, J. Chem. Phys., 84, 2720 (1986).

61. Z. Latajka and S. Scheiner, J. Comp. Chem., 8, 663 (1987)

62. C. Kozmutza and E. Kapuy, J. Comp. Chem., 12, 953 (1991).
63. D. Feller and E.R. Davidson, in Reviews in Computational Chemistry, K.B. Lipkowitz and D.B. Boyd, Eds., VCH, New York, 1990.

64. S.G. Lias, J.E. Bartmess, J.F. Liebman, J.L. Holmes, R.D. Levin, and W.G. Mallard, Gas-Phase Ion and Neutral Thermochemistry; J. Phys. Chem. Ref. Data, vol. 17, suppl. 1, American Chemical Society, Washington, DC, 1988.

65. D.R. Stull, and H. Prophet, in JANAF Thermochemical Tables, National Bureau of Standards, Washington, DC, 1971.

66. G.C. Pimentel and A.L. McClellan, The Hydrogen Bond, W.H. Freeman, San Francisco, CA, 1960.

67. P. Schuster, G. Zundel, and C. Sandorfy, The Hydrogen Bond, North-Holland Publishing Company, New York, 1976.

68. L.A. Curtiss, D.J. Frurip, and M. Blander, J. Chem. Phys., 71, 2703 (1979).

69. A. Beyer, A. Karpten, and P. Schuster, Topics Curr. Chem., 120 (1984).

70. J. Snir, R.A. Nemenoff, and H.A. Scheraga, J. Phys. Chem., 82, 2497 (1978).

71. G. Henderson, J. Chem. Educ., 64, 88 (1987).

72. A.D.H. Clagne and H.J. Bernstein, Spectrochim. Acta, 22A, 807 (1966).

73. A.D.H. Clagne and H.J. Bernstein, Spectrochim. Acta, 25A, 593 (1969).

74. T. Kitao and C.H. Jarboe, J. Org. Chem., 32, 407 (1967).

75. A. Almenningen, O. Bastiansen, and T. Motzfeldt, Acta Chim. Scand., 23, 2849 (1969).

76. Y.-T. Chang, Y. Yamaguchi, W.H. Miller, and H.F. Schaefer, J. Am. Chem. Soc., 109, 7245 (1987).

77. M.L. Huggins, Science, 55, 679 (1922); thesis, University of California, 1919.

78. W.M. Latimer and W.H. Rodebush, J. Am. Chem. Soc., 42, 1419 (1920).

79. S.N. Vinogradov and R.H. Linnell, Hydrogen Bonding, Van Nostrand Reinhold, New York, 1971.

80. J.E. Griffin, Ed., The Hydrogen Bond: New Insights on an Old Story, vol. 22, The American Crystallographic Association, New York, 1986.

81. R.O. Day, K.C. Kumara Swamy, L. Fairchild, J.M. Holmes, and R.R. Holmes, J. Am. Chem. Soc., 113 , 1627 (1991).

82. A.D. DiGabrielle, M.R. Sanderson and T.A. Steitz, Proc. Natl. Acad. Sci. USA, 86, 1816 (1989).

83. A. Goldblum, J. Comp. Chem., 8, 835 (1987).

84. R.J. Vos, R. Hendriks, and F.B. van Duijneveldt, J. Comp. Chem., 11, 1 (1990).

85. S.H. Nilar, J. Comp. Chem., 12, 1008 (1991).

86. L.L. Connell, S.M. Ohline, P.W. Joireman, T.C. Corcoran, and P.M. Felker, J. Chem. Phys., 94, 4668 (1991).

87. A. Engdahl and B. Nelander, J. Chem. Phys., 86, 4831 (1987).

88. K.-P. Schröder, Chem. Phys., 123, 91 (1988).

89. J.L. Derissen, J. Mol. Struct., 7, 67 (1971).

90. Y. Maréchal, in Vibrational Spectra and Structure, vol. 16, J.R. Durig, Ed., Elsevier, New York, 1987.

91. K.I. Peterson, G.T. Fraser, D.D. Nelson, and W. Klemperer, in Comparison of Ab Initio Quantum Chemistry With Experiment for Small Molecules, R.J. Bartlett, Ed., D. Reidel Publishing Company, Boston, MA, 1985.

92. S.E. Novick, K.R. Leopold, and W. Klemperer, in Atomic and Molecular Clusters, E.R. Bernstein, Ed., Elsevier, New York, 1990.

93. D.D. Nelson, G.T. Fraser, and W. Klemperer, Science, 238, 1670 (1987). 
94. C.E. Dykstra and L. Andrews, J. Chem. Phys., 92, 6043 (1990).

95. M. Havenith, R.C. Cohen, K.L. Busarow, D.-H. Gwo, Y.T. Lee, and R.J. Saykally, J. Chem. Phys., 94, 4776 (1991).

96. J.-P. Perchard, R.B. Bohn, and L. Andrews, J. Phys. Chem., 95, 2707 (1991).

97. M.J. Frisch, J.A. Pople, and J.E. Del Bene, J. Phys. Chem., 89, 3664 (1985).

98. M.J. Frisch, J.E. Del Bene, J.S. Binkley, and H.F. Schaefer, J. Chem. Phys., 84, 2279 (1986).
99. J.E. Del Bene, J. Comp. Chem., 10, 603 (1989).

100. Z. Latajka and S. Scheiner, J. Comp. Chem., 8, 674 (1987).

101. G.T. Fraser, R.D. Suenram, F.J. Lovas, and W.J. Stevens, Chem. Phys., 125, 31 (1988).

102. A.C. Legon and D.J. Millen, Chem. Soc. Rev., 21, 71 (1992).

103. S. Schröder, V. Daggett, and P. Kollman, J. Am. Chem. Soc., 113, 8922 (1991).

104. V. Daggett, S. Schröder, and P. Kollman, J. Am. Chem. Soc., 113, 8926 (1991). 